International

Elsevier Editorial System(tm) for Ceramics

Manuscript Draft

Manuscript Number: CERI-D-17-03721R1

Title: SOLUTION COMBUSTION SYNTHESIS OF (Ni,Fe)Cr2O4 PIGMENTS: EFFECT OF POST-SYNTHESIS THERMAL TREATMENTS

Article Type: Full length article

Keywords: Powders: chemical preparation (A); Calcination (A); colour (C); spinels (D); post-synthesis treatments

Corresponding Author: Mrs. Jessica Gilabert, M.Sc.

Corresponding Author's Institution: Instituto de Tecnología Cerámica (ITC). Asociación de Investigación de las Industrias Cerámicas (AICE)

First Author: Jessica Gilabert, M.Sc.

Order of Authors: Jessica Gilabert, M.Sc.; Maria Dolores Palacios, PhD; Maria Jose Orts, PhD; Sergio Mestre, PhD

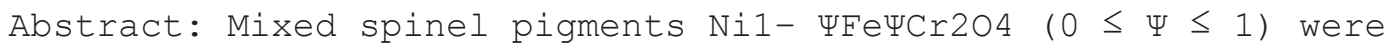
synthesized by means of a method known as Solution Combustion Synthesis, using urea as fuel. Effects on mineralogy, microstructure and colouring power of composition and parameters of post-synthesis thermal treatments (temperature and kiln atmosphere) were studied. The as-synthesized powders were calcined at two different temperatures $\left(800\right.$ and $\left.1000^{\circ} \mathrm{C}\right)$ and atmospheres (oxidizing and inert). Powders were characterized by X-ray diffraction (XRD), thermogravimetry (TG), scanning electron microscopy (FEG-SEM) and colour development in glaze.

Mineralogy was highly affected by post-synthesis parameters. A progressive evolution from a Fd-3m face-centred spinel to a rhombohedral (Fe,Cr) 203 structure was identified as the calcination temperature increased and composition enriched in iron. Inert atmosphere slowed down spinel-(Fe, Cr) 203 transformation. Moreover, crystallite size of both phases showed characteristic critical points with composition and calcination conditions. On the other hand, microstructure analysis showed an important grain growth as the calcination temperature increased using the oxidizing atmosphere, but it was considerably altered with inert atmosphere.

Regardless of post-synthesis thermal treatment parameters, all pigments showed high colouring power in a glaze. As $\Psi$ increased, generated colours evolved from yellow-greenish to brown. Only luminosity coordinate L* of glazes subtly decreased as calcination temperature of the pigment increased, while $a^{*}$ and $b^{*}$ were nearly constant. This behaviour is related to the evolution of the pigment during the heating interval of the firing cycle of the glazed samples. 


\title{
SOLUTION COMBUSTION SYNTHESIS OF
}

\section{$(\mathrm{Ni}, \mathrm{Fe}) \mathrm{Cr}_{2} \mathrm{O}_{4}$ PIGMENTS: EFFECT OF POST-}

\section{SYNTHESIS THERMAL TREATMENTS}

\author{
J. Gilabert ${ }^{\mathrm{a}, *}$, M.D. Palacios ${ }^{\mathrm{b}}$, M.J. Orts ${ }^{\mathrm{b}, \mathrm{c}}$, S. Mestre ${ }^{\mathrm{b}, \mathrm{c}}$
}

${ }^{a}$ Instituto de Tecnología Cerámica. Asociación de Investigación de las Industrias Cerámicas. Castellón (Spain)

${ }^{\mathrm{b}}$ Instituto Universitario de Tecnología Cerámica. Universitat Jaume I. Castellón (Spain)

${ }^{\mathrm{c} D e p a r t a m e n t o ~ d e ~ I n g e n i e r i ́ a ~ Q u i ́ m i c a . ~ U n i v e r s i t a t ~ J a u m e ~ I . ~ C a s t e l l o ́ n ~(S p a i n) ~}$

*Corresponding Author jessica.gilabert@itc.uji.es (Tlf: +34964342424; Fax:

$+34964342425)$

\begin{abstract}
Mixed spinel pigments $\mathrm{Ni}_{1-} \Psi_{\mathrm{Fe}} \mathrm{Cr}_{2} \mathrm{O}_{4}(0 \leq \Psi \leq 1)$ were synthesized by means of a method known as Solution Combustion Synthesis, using urea as fuel. Effects on mineralogy, microstructure and colouring power of composition and parameters of post-synthesis thermal treatments (temperature and kiln atmosphere) were studied. The as-synthesized powders were calcined at two different temperatures (800 and $1000^{\circ} \mathrm{C}$ ) and atmospheres (oxidizing and inert). Powders were characterized by Xray diffraction (XRD), thermogravimetry (TG), scanning electron microscopy (FEGSEM) and colour development in glaze.

Mineralogy was highly affected by post-synthesis parameters. A progressive evolution from a Fd-3m face-centred spinel to a rhombohedral $(\mathrm{Fe}, \mathrm{Cr})_{2} \mathrm{O}_{3}$ structure was identified as the calcination temperature increased and composition enriched in iron. Inert atmosphere slowed down spinel $\rightarrow(\mathrm{Fe}, \mathrm{Cr})_{2} \mathrm{O}_{3}$ transformation. Moreover, crystallite size of both phases showed characteristic critical points with composition
\end{abstract}


and calcination conditions. On the other hand, microstructure analysis showed an important grain growth as the calcination temperature increased using the oxidizing atmosphere, but it was considerably altered with inert atmosphere.

Regardless of post-synthesis thermal treatment parameters, all pigments showed high colouring power in a glaze. As $\Psi$ increased, generated colours evolved from yellowgreenish to brown. Only luminosity coordinate $\mathrm{L}^{*}$ of glazes subtly decreased as calcination temperature of the pigment increased, while $a^{*}$ and $b^{*}$ were nearly constant. This behaviour is related to the evolution of the pigment during the heating interval of the firing cycle of the glazed samples.

Keywords: Powders: chemical preparation (A); Calcination (A); colour (C); spinels (D)

\section{Introduction}

Spinel-type mixed oxides have been used as ceramic pigments because of their thermal and chemical colour stability $[1,2]$ and insolubility into the substrate they are applied [3]. 18 from 44 pigments classified by the Color Pigments Manufacturers Association (CPMA) [4] present spinel-type structure, being considered one of the most important pigment group by the ceramic sector. The formulation of an inorganic pigment for glazed ceramic tiles is not an easy task because of the specific technical requirements to be achieved: chemical resistance to molten glazes, colouring power and thermal stability at temperatures over $1100^{\circ} \mathrm{C}[5-7]$ are some of the most important ones.

Ceramic sector has traditionally manufactured pigments by solid-state reaction among raw materials as oxides, hydroxides and carbonates, applying high calcination temperatures (up to $1400^{\circ} \mathrm{C}$ ) and long soaking times (3-6 hours) [8]. Such a ceramic 
route is really energy intensive and time consuming, and the products are usually inhomogeneous, coarse, impure, and away from stoichiometry because of the thick diffusion barriers resulting from the lack of molecular-level mixing [9]. Digital inkjet decoration of ceramic products is demanding alternative pigment synthesis methodologies to overcome these mentioned drawbacks in order to obtain a broader colour palette and/or reduce processing costs (specially the milling step). To prevent their print head nozzles from clogging by pigment's particles [10-12], is required that $99 \%$ of the particles were less than $1 \mu \mathrm{m}$ in diameter [13-15]. Therefore, ceramic inks are currently prepared from industrial ceramic pigments by means of a highenergy ball milling process to reduce particle size from micrometric to submicrometric range to meet the latest inkjet machines demands.

Solution combustion synthesis (SCS) is an emerging wet-chemical technology appropriate to get over some of the most important limitations that traditional ceramic route presents, since it allows the generation of chemically and thermally stable mixed oxides applying low temperatures and really short soaking times [16]. A general SCS is based on an exothermic reaction between an oxidizer such as metal nitrates and an organic fuel (frequently urea or glycine), being the internal chemical energy the driving force for crystalline lattice formation. In addition, SCS allows some control of the as-synthesized pigment sizes in the nanometric scale, because it inhibits particle size growth and favours a spongy microstructure development. In fact, solution-based combustion synthesis offers advantages in terms of improved compositional homogeneity and purity of the final product, because it begins from an aqueous solution, which assures a molecular-level mixing of reagents. As a result, SCS serves as a promising synthesis route for mass production of nanomaterials in a fast and direct way [9]. 
Nevertheless, SCS process has not been widely studied from a technical point of view, noticing the lack information available on the effects of combustion parameters as fuel [17] and ignition temperature [18] or the reaction mechanisms [19]. In addition, despite SCS general capability to obtain high-purity products as relevant bibliography states $[19,20]$, some studies have demonstrated the appearance of secondary products and fuel traces that can damage pigment's final behaviour, specially under fuel-rich condition $[3,4]$. In our case, these secondary phases could react during the firing cycle of the glazes that contain the SCS pigments, changing his nature and generating unexpected effects over the properties of the final product. Therefore, studying the effect of applying a second thermal treatment on the assynthesized SCS pigment is highly required to evaluate the evolution of the pigment (crystalline phases, microstructure and colouring power) with the parameters of the thermal cycle, in order to understand pigment evolution during the firing cycle of the glaze.

The present research is aimed at studying the effect of post-synthesis calcination temperature $\left(\mathrm{T}_{\mathrm{c}}\right)$ and kiln atmosphere on the evolution of spinel-type pigments $\mathrm{Ni}_{1-\Psi} \mathrm{Fe}_{\Psi} \mathrm{Cr}_{2} \mathrm{O}_{4}(0.0 \leq \Psi \leq 1.0)$ synthesized by Solution Combustion Synthesis, using urea as fuel. As reported, there are relevant studies which apply a calcination process after combustion $[1,3,21,22]$, but little attention has been paid to this stage when observing its effect on the as-synthesized product. In fact, there is a growing uncertainty about the changes undertaken in pigment characteristics when it is added to a glaze until the very first moment in which it starts to melt.

$\mathrm{NiCr}_{2} \mathrm{O}_{4}$ and $\mathrm{FeCr}_{2} \mathrm{O}_{4}$ selected pigments present a high technological interest in the ceramic industry [23], since they are frequently used to generate green and brown shades respectively. Introducing appropriate procedures in SCS is supposed to result 
in a good control of mineralogy and particle morphology. In this way, the study of the effects of the parameters of secondary thermal treatment is considered an essential factor in regards to optimize the performance of the pigments.

\section{Experimental procedure}

\subsection{Material and methods}

Solid solutions between nickel and iron chromites $\mathrm{Ni}_{1-\Psi} \mathrm{Fe}_{\Psi} \mathrm{Cr}_{2} \mathrm{O}_{4}(0.0 \leq \Psi \leq 1.0)$ have been synthesized by solution combustion synthesis in steps $\Delta \Psi=0.2$.

Corresponding metal nitrates were weighted according to their molar proportions, following Table 1, and then dissolved in $50 \mathrm{~mL}$ of distilled water adding $24 \mathrm{~g}$ of urea as fuel. Fuel/oxidizer molar ratio was maintained constant (6/40) to limit the number of variables in the study. SCS route was carried out using all reagents of analytical grade from Panreac Quimica.

The aqueous solution was vigorously stirred in a $700-\mathrm{mL}$ pyrex container previously to carry out the combustion process in a preheated kiln at $500{ }^{\circ} \mathrm{C}(\mathrm{BLF} 1800$, Carbolite Furnaces Ltd, UK) with 20 min of soaking time to favour the complete combustion reaction. During soaking time, the sample dries, boils, foam, ignites and burns achieving temperatures around $1500^{\circ} \mathrm{C}$ [16]. Moreover, heat transfer takes some time, and this 20 -min period allows sample cooling and reduce the thermal gradients that can damage the containers.

After SCS process, samples were calcined at $800^{\circ} \mathrm{C}$ and $1000^{\circ} \mathrm{C}$ in air for $1 \mathrm{~h}$ in an electric furnace (RHF 1600, Carbolite Furnaces Ltd, UK). Additionally, pigment calcination at the higher temperature was also carried out in nitrogen atmosphere in a tubular kiln (HST 12/400, Carbolite Furnaces Ltd, UK). 
All pigments were ball milled (Pulverisette 5, Fritsch GmbH, Germany) with water at $260 \mathrm{rpm}$ for $15 \mathrm{~min}$, dried under infrared lights and sieved through a $200 \mu \mathrm{m}$ mesh.

Finally, pigments were mixed in a $2 / 98 \mathrm{wt} \%$ proportion into a transparent singlefired porous tile glaze (chemical composition: $0.5 \% \mathrm{Na}_{2} \mathrm{O} 4.0 \% \mathrm{~K}_{2} \mathrm{O}, 15.3 \% \mathrm{CaO}$, $\left.0.9 \mathrm{MgO}, 9.0 \% \mathrm{ZnO}, 7.4 \% \mathrm{Al}_{2} \mathrm{O}_{3}, 3.0 \% \mathrm{~B}_{2} \mathrm{O}_{3}, 59.5 \% \mathrm{SiO}_{2}\right)$ and fired in an electric laboratory furnace according to an optimized thermal cycle of single-fired floor tile (maximum temperature $1100{ }^{\circ} \mathrm{C}$ and 6 min of soaking time). All process has been summarized in Fig. 1, where the followed SCS process scheme is described.

\subsection{Pigment characterization}

Characterization of crystalline structures was performed using an X-ray diffractometer (Theta-Theta D8 Advance, Bruker, Germany), with CuK radiation ( $\lambda$ $=1.54183 \AA$ ). The generator applied an intensity light source of $45 \mathrm{kV}$ and $40 \mathrm{~mA}$. XRD data were collected by means of a VÅNTEC- 1 detector in a $2 \theta$ from 5 to $90^{\circ}$ with a step width of $0.015^{\circ}$ and a counting time of $1.2 \mathrm{~s} / \mathrm{step}$. Phase quantification was carried out by Rietveld method using DIFFRACplus TOPAS (version 4.2). The agreement indices, as defined in Topas, for the final least-squares cycles of all refinements were in the following ranges: $1.06 \leq \mathrm{Rwp}$ (Weight profile R-factor) $\leq$ 2.44 and $1.01 \leq \mathrm{GOF}$ (Goodness of fit $) \leq 1.25$.

Simultaneous thermal analysis (ATD-TG) were conducted with a TGA-SDTA 851E/160 (Mettler Toledo, Switzerland). Thermal treatment conditions consisted of a heating process in a platinum vessel from 25 to $1000^{\circ} \mathrm{C}$ at $10^{\circ} \mathrm{C} / \mathrm{min}$ using two dynamic atmospheres (50 $\mathrm{mL} / \mathrm{min}$ flow), air and nitrogen, respectively. 
Microstructural characterization was performed with a FEG-SEM (QUANTA 200F, FEI Co, USA) and specific surface area values were determined according to the BET method (Brunauer-Emmet-Teller) using nitrogen gas as adsorbate (Tristar 3000, Micromeritics, USA) and a degassing temperature of $150^{\circ} \mathrm{C}$ for 3 hour.

Colour of the glazed tiles was evaluated with a spectrophotometer (Color Eye 7000A, X-Rite Inc, USA), and CIELab* chromatic coordinates were calculated using CIE Illuminant D65 and CIE $10^{\circ}$ standard observer.

\title{
3 Results and discussion
}

\begin{abstract}
After SCS combustion, materials with low bulk density and very spongy appearance were obtained (Fig. 1), increasing practically ten times the volume occupied by the liquid precursor. They were easy to disaggregate, without needing an additional grinding process.
\end{abstract}

\subsection{Crystalline structure}

All as-synthesized pigments contain a phase with a spinel-type Fd-3m face centred structure [24]. Furthermore, a crystalline secondary phase with a rhombohedral eskolaite-type structure appeared progressively as $\Psi$ increased, which was identified as a solid solution between iron and chromium trioxides (chemical formula $\left.(\mathrm{Fe}, \mathrm{Cr})_{2} \mathrm{O}_{3}\right)$. In Fig. 2, XRD analysis for as-synthesized and calcined pigments at $\mathrm{T}_{\mathrm{c}}=$ $1000^{\circ} \mathrm{C}$ are detailed. Both crystalline phases have been labeled in their corresponding positions after identification. Results show that the mineralogy of the pigments evolved with $\Psi$. On one hand, spinel reflections shifted towards lower angles as the composition enriched in iron, following the evolution of the solid solutions between both extreme spinels $(\Psi=0.0$ and $\Psi=1.0)[25,26]$. 
Table 2 shows crystal structural data of as-synthesized pigments: unit cell parameters (lattice parameters and oxygen coordinate of spinel phase) and estimated crystal chemistry of all phases formed in the as-synthesized and calcined pigments. Crystal chemistry data were calculated applying a property balance approximation using the corresponding mass and atomic balances between the initial solution and the proportions of $\mathrm{Ni}_{1-\mathrm{x}} \mathrm{Fe}_{\mathrm{x}} \mathrm{Cr}_{2-\mathrm{y}} \mathrm{Fe}_{\mathrm{y}} \mathrm{O}_{4}$ and $\mathrm{Cr}_{2-\mathrm{z}} \mathrm{Fe}_{\mathrm{z}} \mathrm{O}_{3}$ phases obtained by Rietveld's method. The equations' system was solved by a least squares method to minimize the differences between the calculated and the experimental data. All results are shown in Table 2, except for the $y$ index which has a value lower than 0.01 in all the samples. Taking into account the uncertainties of the results of the Rietveld analysis, this value was considered not significant.

The results obtained pointed to a practically fixed $\mathrm{Fe} / \mathrm{Cr}$ ratio in the as-synthesized eskolaite-type phase, around 0.6. However, after the thermal treatments, this ratio slightly increased, tending to a value of $2 / 3$, being this trend clearer as the initial composition enriched in iron. This result is logical since the compositions with $\Psi=1.0$ corresponds to this stoichiometric relation. On the other hand, this result means that the eskolaite-type phase stoichiometry is relatively narrow despite the wide range of initial compositions tested.

In the case of the spinel phase, its composition in the as-synthesized pigments was progressively richer in iron as the initial solution was increasing the proportion of this element. The pigments annealed under air atmosphere after the synthesis contained only the $\mathrm{NiCr}_{2} \mathrm{O}_{4}$ spinel, except the pigments with $\Psi=1.0$. The pigments annealed under nitrogen, contained the spinel $\mathrm{NiCr}_{2} \mathrm{O}_{4}$ only if the iron proportion in the initial solution was low $(\Psi \leq 0.4)$, but for higher proportions of iron, a mixed spinel was obtained. 
The thermodynamic criteria seem to explain the effect of $T_{c}$ over crystalline phase's evolution. When samples were calcined in oxidizing atmosphere, only if composition was iron-free $(\Psi=0.0)$, a spinel was the unique crystalline phase present in the product. In the rest of the calcined samples, $(\mathrm{Fe}, \mathrm{Cr})_{2} \mathrm{O}_{3}$ was also present. According to Fig. 3 a, as the composition enriches in iron, the transformation of spinel to $(\mathrm{Fe}, \mathrm{Cr})_{2} \mathrm{O}_{3}$ is progressively more favourable as $\mathrm{Fe}(\mathrm{II})$ is oxidized to $\mathrm{Fe}(\mathrm{III})$. Finally, nickel-free composition ( $\Psi=1.0)$ gives calcined pigments without spinel. Thus, a thermal treatment combined with an oxidizing atmosphere favour the transformation spinel $\rightarrow(\mathrm{Fe}, \mathrm{Cr})_{2} \mathrm{O}_{3}$. Probably, the thermodynamic trend towards obtaining the most stable crystalline phase between iron, chromium and oxygen ions is coupled with enough thermal energy to overcome the activation energy of the transformation.

The spinel $\rightarrow(\mathrm{Fe}, \mathrm{Cr})_{2} \mathrm{O}_{3}$ transformation involves the oxidation of iron. Therefore, the composition of the atmosphere during calcination was another parameter to analyse. When pigments were calcined in nitrogen atmosphere, spinel was the only crystalline phase obtained if $\Psi=0.0$, as in the case of oxidizing environment (Fig. 3 b).

Nevertheless, when iron enrichment was evident, the spinel $\rightarrow(\mathrm{Fe}, \mathrm{Cr})_{2} \mathrm{O}_{3}$ transformation slowed down with respect to the oxidizing treatments. This fact confirms the effect of calcination atmosphere over phase transformation. Thus, using inert atmospheres, some percentage of spinel-type phase could be maintained in the pigment. Probably, a slightly reducing atmosphere can stop the spinel $\rightarrow(\mathrm{Fe}, \mathrm{Cr})_{2} \mathrm{O}_{3}$ transformation. However, the pigment would again be in contact with the oxygen during its application.

In Fig. $4 \mathrm{a}$ and $4 \mathrm{~b}$ the evolution of the mass percentages calculated for both crystalline phases after Rietveld refinement is represented, evidencing the low 
proportion of $(\mathrm{Fe}, \mathrm{Cr})_{2} \mathrm{O}_{3}$ present in the as-synthesized pigments, which did not exceed $10 \%$ wt in any sample. Therefore, SCS method can be thought to allow obtaining nearly single-phase spinel-type pigments from the original nitrate reagents, without having the necessity of applying additional thermal treatments after the combustion process. These results also show the clear advance in the spinel $\rightarrow(\mathrm{Fe}, \mathrm{Cr})_{2} \mathrm{O}_{3}$ transformation after applying a calcination processes in oxidizing atmosphere. However, an effect of $\mathrm{T}_{\mathrm{c}}$ value over $(\mathrm{Fe}, \mathrm{Cr})_{2} \mathrm{O}_{3}$ percentage was not detected, which means that the transformation is thermodynamically controlled, at least in the investigated interval of $\mathrm{T}_{\mathrm{c}}$. When enough thermal energy is available, the system reaches the equilibrium with a relatively fast kinetics. On the other hand, the effect of inert atmosphere over $(\mathrm{Fe}, \mathrm{Cr})_{2} \mathrm{O}_{3}$ percentage was only clear for pigments with $\Psi \geq 0.6$. It is possible that the bed of particles had retained enough oxygen to sustain the transformation when it occurs to a small extent, but not when a larger extent is possible.

The results demonstrated an unwanted behaviour of the $\mathrm{NiCr}_{2} \mathrm{O}_{4}-\mathrm{FeCr}_{2} \mathrm{O}_{4}$ system. The iron-rich spinels obtained by SCS are not thermodynamically stable, and their evolution towards the secondary phase $(\mathrm{Fe}, \mathrm{Cr})_{2} \mathrm{O}_{3}$ is activated by temperature and can be partially controlled by modifying the composition of the calcination atmosphere.

According to Muan et al. [27], iron-chromium spinel is not thermodynamically stable under $1400^{\circ} \mathrm{C}$, and shifts to the $(\mathrm{Fe}, \mathrm{Cr})_{2} \mathrm{O}_{3}$ phase, which is the stable crystalline phase. In addition, Dondi et al. [28] stated that Fe(II) is known to be easily oxidized in "ceramic conditions" to the point it is retained only when $\mathrm{Cr}(\mathrm{III})$ saturates the occupancy of the octahedral site. In other words, the synthesized $\mathrm{FeCr}_{2} \mathrm{O}_{4}$ is a metastable phase at room temperature obtained thanks to the fast kinetics of SCS 
process, which prevents from reaching the system's equilibrium. An open question is the possibility of having some substitution of Ni(II) by Fe(III) in the tetrahedral sites of the spinel, also as a consequence of SCS's kinetics, leaving some vacancies in order to maintain the electroneutrality.

Crystallite size of spinel and $(\mathrm{Fe}, \mathrm{Cr})_{2} \mathrm{O}_{3}$ solid solution phases was also calculated (Fig. $4 \mathrm{c}$ and $4 \mathrm{~d}$ respectively). When phase percentages were lower than $5 \% \mathrm{wt}$. crystallite size determinations presented a lack of precision, being omitted from the representations.

$\mathrm{NiCr}_{2} \mathrm{O}_{4}$ pigments showed a crystallite size around $50 \mathrm{~nm}$ that was nearly independent of their thermal history (Fig. 4 c). However, as Ni was progressively substituted by iron, spinel's crystallite size showed a parabolic-like trend, reaching a maximum of approximately $80 \mathrm{~nm}$ at intermediate compositions $(0.2 \leq \Psi \leq 0.4)$. The curve was shifted to higher crystallite sizes when a second thermal treatment was applied, being the displacement as bigger as higher was $\mathrm{T}_{\mathrm{c}}$. In addition, the maximum was displaced to $\Psi=0.6\left(120 \mathrm{~nm}\right.$ for $\left.\mathrm{T}_{\mathrm{c}}=1000{ }^{\circ} \mathrm{C}\right)$. Finally, an inert atmosphere during the calcination slowed the crystallite growth with respect to an oxidizing one. In consequence, iron addition in low proportions favoured crystallite growth and spinel crystallinity. Nevertheless, as $\Psi$ increased beyond 0.6 , crystallite size decreased markedly, reaching values near $40 \mathrm{~nm}$ for $\Psi=1.0$ (in the samples where spinel was present). Obviously, there were two effects competing during the calcination. On one hand, the spinel's crystallite growth. On the other hand, the spinel $\rightarrow(\mathrm{Fe}, \mathrm{Cr})_{2} \mathrm{O}_{3}$ transformation, which could limit the maximum crystallite size of the remaining spinel. The combined effect was the presence of a critical point in the crystallite size. 
The (Fe, Cr $)_{2} \mathrm{O}_{3}$ crystallite size also showed a complex evolution (Fig. 4 d). In the case of the as-synthesized pigments, crystallite size decreased from $70 \mathrm{~nm}$ to $40 \mathrm{~nm}$ nearly lineally as $\Psi$ increased. However, crystallite size always increased after a thermal treatment but the increase was a function of $\Psi$ and $T_{c}$, without a clear effect of calcination atmosphere. As a result, a minimum appeared at $\Psi=0.4$ but the crystallite size was larger as calcination temperature was higher, reaching $120 \mathrm{~nm}$ for $\mathrm{T}_{\mathrm{c}}=1000{ }^{\circ} \mathrm{C}$ and $\Psi=1.0$. This behaviour is complementary of the spinel's crystallite size. The growth of the $(\mathrm{Fe}, \mathrm{Cr})_{2} \mathrm{O}_{3}$ crystallites is limited by the progress of the spinel $\rightarrow(\mathrm{Fe}, \mathrm{Cr})_{2} \mathrm{O}_{3}$ transformation.

Spinel phase lattice parameters were also evaluated with $\Psi$ (Fig. 5). As-synthesized samples and the ones calcined in an oxidizing atmosphere followed a sigmoidal behaviour, which was far from the lineal trend stated by Vegard's law as it was described in previous works carried out by Gilabert et al. [29] in other spinel-type systems. Estimated behaviour according to Vegard's law showed in Fig. 5 is based on the ICCD data from the spinels $\mathrm{NiCr}_{2} \mathrm{O}_{4}(\Psi=0.0)[25]$ and $\mathrm{FeCr}_{2} \mathrm{O}_{4}(\Psi=1.0)$ [26], respectively. Despite deviating from the theoretical trend, the lattice parameter evolution was similar to the one described previously by authors as Mestre et al. [30], where spinel studied also contained iron. In consequence, it seems that the presence of iron promotes this characteristic sigmoidal behaviour, which leads to lower lattice parameters than expected. In addition, as the $T_{c}$ increased, the decrease of lattice parameter with respect to the expected one was higher, pointing that the cell volume of the spinel remaining after the thermal treatment was lower. In the case of the pigments thermally treated in inert atmosphere, the observed trend was completely different, as lattice parameter presented a strongly parabolic decreasing trend. A hypothesis could be proposed to interpret this behaviour. The 
spinel $\rightarrow(\mathrm{Fe}, \mathrm{Cr})_{2} \mathrm{O}_{3}$ transformation involves the transport of iron ions from the spinel to the growing $(\mathrm{Fe}, \mathrm{Cr})_{2} \mathrm{O}_{3}$ network and its oxidation. Therefore, the number of vacancies in the iron positions of the spinel increases strengthening distances between ions and reducing the lattice parameter. The calcination in nitrogen atmosphere leads to a loss of oxygen atoms in the structure, creating additional vacancies and a further decrease in the lattice parameter. This hypothesis is not a substantiated evidence but, taking into account the lack of research about this subject, it seems to be the most reasonable explanation about the observed behaviour. More sophisticated analytical techniques are required to confirm the hypothesis or give an alternative interpretation.

\subsection{Thermal behaviour}

Thermogravimetric analyses were carried out to characterize the evolution of the $\mathrm{Fe}(\mathrm{II})$ to $\mathrm{Fe}(\mathrm{III})$ oxidation process related with spinel $\rightarrow(\mathrm{Fe}, \mathrm{Cr})_{2} \mathrm{O}_{3}$ transformation. The $\Psi=1.0$ as-synthesized sample was tested in oxidizing and inert atmospheres (Fig. 6). The DTA curves were also obtained but the small energetic changes were masked by the noisy background. A common behaviour was observed in both tests. Firstly, a progressive mass loss $\left(25-400^{\circ} \mathrm{C}\right)$ corresponding to two simultaneous thermal processes: the loss of residual humidity or dehydration process $\left(25-150^{\circ} \mathrm{C}\right)$ and dehydroxylation process due to non-crystallized hydroxides generated as a result of the wet-milling process $\left(200-400^{\circ} \mathrm{C}\right)$. In addition, some percentage of this initial mass loss could be related to an amount of residual gasification components in the obtained powders, which can be emitted at those temperatures, as a result of a lower reaction effectiveness [31,32]. 
The process was followed by a subtle mass increase assigned to the partial iron oxidation process, which was correlated with spinel $\rightarrow(\mathrm{Fe}, \mathrm{Cr})_{2} \mathrm{O}_{3}$ transformation [33]. Finally, a further mass loss was detected after iron oxidation that could be assigned to a chromium oxide loss as volatile species as this mechanism has been identified in the synthesis of $(\mathrm{Fe}, \mathrm{Cr})_{2} \mathrm{O}_{3}$ black pigment [34]. However, despite the similar behaviour, considerable differences were detected in the magnitude of the observed changes. On one hand, water loss covers a broader interval and oxidation process began at higher temperatures $\left(570^{\circ} \mathrm{C}\right.$ approximately) working in inert atmosphere. On the other hand, water loss was overlapped with the beginning of the oxidation step, approximately at $420^{\circ} \mathrm{C}$, when oxygen-rich atmosphere was used. Oxidizing atmosphere favours iron oxidation and the global mass loss is lower than in the inert atmosphere because iron is not oxidised in the same proportions. Stoichiometric calculation estimates a mass increase of $3.5 \%$ for the transformation of $\mathrm{FeCr}_{2} \mathrm{O}_{4}$ to $\mathrm{Fe}_{0.67} \mathrm{Cr}_{1.33} \mathrm{O}_{3}$ solid solution. Considering that the water loss was the same under the two atmospheres, iron oxidation supposes a mass increase of $1.5 \%$ under air and a $0.5 \%$ under nitrogen, values which reflect the effect of atmosphere. Probably, the source of oxygen in the inert atmosphere test was air retained between the sample particles, whose quantity was limited, the same case that the calcination in the tubular furnace. In conclusion, atmosphere strongly influences the iron oxidation, and indirectly influences the phase transformation. Owing to this reason, an oxygen rich atmosphere during calcination will favour the spinel $\rightarrow(\mathrm{Fe}, \mathrm{Cr})_{2} \mathrm{O}_{3}$ transformation. Therefore, this transformation can occur when glazes containing the pigment are fired in a furnace. 


\subsection{Morphological characterization}

The study of grain morphology showed an evident influence of composition, $T_{c}$ and calcination atmosphere, over the final grain shape and size and porosity (Fig. 7), effects that are also reflected in specific surface area values (Table 3).

As-synthesized pigments images demonstrated that $\Psi=0.0$ sample had larger grains than the $\Psi=1.0$ one, but with more voids between them, which is coherent with their higher surface area. Taking into account that both samples contained very high proportions of spinel, grain growth is favoured in Ni-rich spinel, but the sintering process does not progress in the same extent.

After the post-synthesis thermal treatment in air, the microstructure of the samples was very different. On one hand, $\Psi=0.0$ sample showed a heterogeneous grain growth. As a result, some grains clearly presented the spinel crystalline habit [35], and an increase in porosity was detected, which clearly correlates with the increase in specific surface area. The lack of homogeneity could be caused by the Ostwald's ripening mechanism coupled with a gas-phase transport of chromium oxide. Escardino et al. [34] studied this kind of grain growth that promotes the appearance of an intergrain porosity caused by chromium oxide transport in gas phase from smaller decreasing-size particles to the bigger increasing-size ones. In addition, this gas phase transport favours the development of the crystalline habit. On the other hand, the $\Psi=1.0$ sample showed a nearly regular grain growth, which generates a microstructure of sintered grains with low porosity, and consequently, with a lower specific surface area. In this case, the crystalline habit of eskolaite-type structure of $(\mathrm{Fe}, \mathrm{Cr})_{2} \mathrm{O}_{3}$ phase, the only phase present, was not clearly detected. However, the 
larger grains tended to develop flat surfaces, probably an intermediate step in the development of the crystalline habit.

The microstructure of samples treated in inert atmosphere showed big differences with their counterparts treated in air, pointing to a clear effect of oxygen. On one hand, the grain size of $\Psi=0.0$ sample was very similar to the as-synthesized one. In other words, the grain growth had been slowed down, but sintering has advanced through some surface-transport mechanism as demonstrates the reduction observed in specific surface area. On the other hand, the $\Psi=1.0$ sample has a grain size and specific surface area similar to the air-treated one, but with less agglomerated grains. It can be thought that the chromium transport was more difficult in a $\mathrm{N}_{2}$ rich atmosphere and grain growth was very slow $(\Psi=0.0$ case $)$. However, other transport mechanisms, as surface diffusion, are present in $\Psi=1.0$ case because the grain growth was of the same order in the two atmospheres.

\subsection{Colouring power}

All pigments showed a high colouring power in the glaze, regardless of their thermal history (Fig. 8). Generated colours evolved from green-yellowish tones to brownish shades. Neither heterogeneities nor other defects (bubbles or pinholes) were appreciated in any glaze, which indicated a good homogeneity of the pigments.

The spectrophotometric curves (Fig. 9) were a function of composition and the parameters of the second thermal treatment (atmosphere and $\mathrm{T}_{\mathrm{c}}$ ). Only curves obtained for $\Psi=0.0$ showed reflectance at wavelengths in the green $(450 \leq \lambda \leq 550)$, blue $(350 \leq \lambda \leq 450)$ and red $(\lambda \geq 650)$ intervals at the same time. For $\Psi \geq 0.0$ an important reduction of reflectance was produced since pigments strongly absorbed nearly all visible spectrum, generating colours in the dark brown palette, and were 
less sensitive to thermal history. When nickel was absent $(\Psi=1.0)$, reflectance increased the yellow $(600<\lambda<650)$ and red intervals $(\lambda \geq 650)$, which corresponds to lighter brown shades.

Regardless obtaining brown tones with the $(\mathrm{Fe}, \mathrm{Cr})_{2} \mathrm{O}_{3}$-containing pigments, it must be stand out that the actual colour of $(\mathrm{Fe}, \mathrm{Cr})_{2} \mathrm{O}_{3}$ is black $[36,37]$. The discrepancy is related to the interaction with the divalent cations present in the ceramic glaze, especially owing to the $\mathrm{Zn}(\mathrm{II})$ influence. Previous experiences in traditional ceramic pigment synthesis [38] pointed out that the $(\mathrm{Fe}, \mathrm{Cr})_{2} \mathrm{O}_{3}$ solid solution is a good black pigment in porcelain tiles (with few divalent cations to react with). However, incorporated into a glaze, the $(\mathrm{Fe}, \mathrm{Cr})_{2} \mathrm{O}_{3}$ reacts with divalent ions, probably generating a structure related with $\mathrm{Zn}(\mathrm{Fe}, \mathrm{Cr})_{2} \mathrm{O}_{4}$ brown spinel.

Regarding post-synthesis parameters, no substantial changes were observed in reflectance spectra, obtaining similar colours in all cases regardless $T_{c}$ and atmosphere changes. This behaviour could indicate that whether SCS samples or the calcined ones evolve to a very similar material during the heating section of the firing of the glaze (up to $1100^{\circ} \mathrm{C}$ ). This fact combined with the interaction between divalent cations and $(\mathrm{Fe}, \mathrm{Cr})_{2} \mathrm{O}_{3}$ phase, when present, results in very low differences in colouring power.

CIELab* chromatic coordinates evolution showed important changes with composition but not with thermal history (Fig. 10). Whether $\mathrm{L}^{*}$ or $\mathrm{b}^{*}$ coordinates (Fig. 10 a) presented a minimum value at $\Psi=0.4$, corresponding to the darker and less-yellowish colour. As the composition enriched in iron, a lightening in colour was obtained with a higher yellow component responsible for the brownish tones. Regarding a* coordinate evolution (Fig. 10 b), the most pronounced one with a 20- 
point variation, it presented a step increase between $\Psi=0.0$ and $\Psi \geq 0.2$, changing from green to red component. Further increases in iron proportion provoked a nearly linear growth of red component.

Chromatic coordinates showed little variation with calcination conditions, although darker tones were obtained with calcined pigments. A Fact that may be due to a higher pigment particle size due to sintering, which reduces the effect of pigmentglaze interaction. The rest of the coordinates did not seem to be appreciably modified.

Colouring power of the pigments obtained by SCS showed a high stability against post-synthesis thermal treatments. Such conditions can modify the crystalline structure, but not surely enough to generate variations in the final colour generated in the glaze, which is extremely important when implementing the SCS technique at an industrial scale.

\section{Conclusions}

Influence of post-synthesis thermal treatment parameters (temperature and kiln atmosphere) over product's characteristics was studied for $\mathrm{Ni}_{1-\Psi} \mathrm{Fe}_{\Psi} \mathrm{Cr}_{2} \mathrm{O}_{4}(0.0 \leq \Psi \leq$ 1.0) pigments obtained by Solution Combustion Synthesis. Results showed an important influence of calcination process over the mineralogy and crystalline parameters. As-synthesized pigments were composed mainly by Fd-3m spinel-type structure $(>90 \% \mathrm{wt})$. However, the presence of iron along with the calcination process (higher temperatures and oxidizing atmosphere) progressively favoured the transformation of the spinel into the eskolaite-type solid solution $(\mathrm{Fe}, \mathrm{Cr})_{2} \mathrm{O}_{3}$, thermodynamically more stable in that conditions, whose proportion evolved linearly with iron enrichment. Inert atmosphere slows down this transformation, and a 
proportion of spinel-type structure remains in all compositional range. Crystallite size of spinel and $(\mathrm{Fe}, \mathrm{Cr})_{2} \mathrm{O}_{3}$ phase presented a complex behaviour with critical points around $\Psi=0.4$ (maximum and minimum respectively). Spinel lattice parameter evolution deviates from Vegard's law, especially for iron-rich pigments, that presented lower values than expected, a possible signal of vacancies in the structure. TG results corroborated that atmosphere greatly influences the oxidation of iron, a process related with the spinel to $(\mathrm{Fe}, \mathrm{Cr})_{2} \mathrm{O}_{3}$ transformation. Microstructural studies showed an important grain growth after the second thermal treatment, unless inert atmosphere was applied. In such a case, the grain growth is a function of pigment's composition.

Colouring power in a glaze depends little on thermal history of pigments. All pigments showed high colour stability independently of calcination temperature and kiln atmosphere. Luminosity parameter $\mathrm{L}^{*}$ was the unique coordinate subtly affected by increasing calcination temperature, obtaining darker colours in all cases. The heating interval of the glaze firing cycle seems to transform the pigments from the as-synthesized mineralogy towards the ones obtained after calcination at $1000^{\circ} \mathrm{C}$. Thus, the study of the effects of calcination processes is essential in order to understand internal changes taken place in mineralogy, microstructure and morphology during glazing process, because they are responsible for the final colour development.

\section{Acknowledgements}

The authors thank Universitat Jaume I for their support for the development of this research (Project Nr. P11B2015-04).

\section{Bibliography}


[1] M. C. Gardey Merino, A. L. Estrella, M. E. Rodriguez, L. Acuña, M. S. Lassa, G. E. Lascalea, P. Vázquez, Combustion syntheses of $\mathrm{CoAl}_{2} \mathrm{O}_{4}$ powders using different fuels, Procedia Materials Science 8 (2015) 519 - 525. doi: 10.1016/j.mspro.2015.04.104

[2] E. Bondoli, T. Manfredini, Pigmentos inorgánicos: concepción, proyecto, producción y aplicaciones industriales, Ceram. Inform. 259 (1999) 45-50.

[3] S. Salem, S H. Jazayeri, A. Allahverdi, F. Bondioli A. M. Ferrari, $\mathrm{CoAl}_{2} \mathrm{O}_{4} \mathrm{Nano}$ pigment obtained by combustion synthesis, Int. J. Appl. Ceram. Technol. 9 (5) (2012) 968-978. doi:10.1111/j.1744-7402.2011.02704.x

[4] Color Pigments Manufacturers Association (CPMA), Classification and chemical descriptions of the complex inorganic color pigments, fourth ed., Alexandria (VA), 2013.

[5] M.F. Gazulla, M.P. Gómez, A. Barba, M. Orduña, Chemical and phase characterization of ceramic pigments, X-ray Spectrometry 36 (2) (2007) 82-91. doi: $10.1002 /$ xrs. 943

[6] J.M. Rincón, J. Carda, J. Alarcón (ed.), Nuevos productos y tecnologías de esmaltes y pigmentos cerámicos. Castellón: Faenza Edetrice Ibérica; Arganda del Rey: Socied, 1992

[7] J.L. Amorós, Glazes for ceramic wall and floor tiles: Evolution and perspectives, Tile Brick Int. 9(5) (1993) 273-278

[8] P. Escribano, J.B. Carda, E. Cordoncillo, Esmaltes y pigmentos cerámicos, Faenza Editrice, Castellón, 2001.

[9] W. Wen, J.M. Wu, Nanomaterials via solution combustion synthesis: a step nearer to controllability, RSC Adv. 4 (2014) 58090-58100. doi: 10.1039/c4ra10145f 
[10] I. Hutchings, Ink-jet printing for the decoration of ceramic tiles: technology and opportunities, Proceedings of the 12th World Congress on Ceramic Tile Quality, 2010, Castellón, Spain, 1-16.

[11] M. Dondi, M. Blosi, D. Gardini, C. Zanelli, P. Zannini, Ink technology for digital decoration of ceramic tiles: an overview, Proceedings of the 13th World Congress on Ceramic Tile Quality, Qualicer 2014, Castellón, Spain, 1-14.

[12] G. L. Güngör, A. Kara, M. Blosi, D. Gardini, G. Guarini, C. Zanelli, M. Dondi, Micronizing ceramic pigments for inkjet printing: Part I. Grindability and particle size distribution, Ceram. Int. 41 (5A) (2015) 6498-6506. doi: 10.1016/j.ceramint.2015.01.093

[13] C. Zanelli, G. L. Güngör, A. Kara, M. Blosi, D. Gardini, G. Guarini, M. Dondi, Micronizing ceramic pigments for inkjet printing: Part II. Effect on phase composition and color, Ceram. Int. 41 (2015) 6507-6517. doi: 10.1016/j.ceramint.2015.01.158

[14] P.M.T. Cavalcante, M. Dondi, G. Guarini, M. Raimondo, G. Baldi, Color performance of ceramic nano-pigments, Dyes Pigm. 80 (2009) 226-232. doi: 10.1016/j.dyepig.2008.07.004

[15] A. Kwade, L. Blecher, J. Schwedes, Motion and stress intensity of grinding beads in a stirred media mill. Part 2: Stress intensity and its effect on comminution, Powder Technol. 86 (1996) 69-76. doi:10.1016/0032-5910(95)03039-5

[16] K.C. Patil, M.S. Hedge, T. Rattan, S.T. Aruna, Chemistry of nanocrystalline oxide materials: Combustion synthesis, properties and applications, World Scientific Publishing, Singapore, 2008. 
[17] J. Gilabert, M.D. Palacios, V. Sanz, S. Mestre, Fuel effect on solution combustion synthesis of $\mathrm{Co}(\mathrm{Cr}, \mathrm{Al})_{2} \mathrm{O}_{4}$ pigments, Bol. Soc. Esp. Ceram. V. XX (2017) XX-XX. doi: 10.1016/j.bsecv.2017.03.003 (IN PRESS)

[18] S.T. Aruna, Solution combustion synthesis-An overview, in: M. Lackner (Ed.), Combustion Synthesis: Novel routes to novel materials, Viena University of Technology, Austria, 2010, pp. 206-221.

[19] A.S. Mukasyan, P. Epstein, P. Dinka, Solution combustion synthesis of nanomaterials, P. Combust. Inst. $31 \quad$ (2007) 1789-1795. doi:10.1016/j.proci.2006.07.052

[20] A. Alves, C.P. Bergmann, F.A. Bellutti, Novel synthesis and characterization of nanostructured materials, Springer-Verlag Berlin Heidelberg, 2013. doi: $10.1007 / 978-3-642-41275-2$

[21] K.C. Patil, T. Mimani, Solution combustión synthesis of nanoscale oxides and their composites, Mater. Phys. Mech. 4 (2001) 134-137

[22] D. Pereira, C. Fraga, V. Caldas, Influence of fuel on morphology of LSM powders obtained by solution combustion synthesis, Powder Technol. 269 (2015) 481-487. doi: 10.4028/www.scientific.net/MSF.727-728.1329

[23] P. Escribano, J.B. Carda, E. Cordoncillo, Esmaltes y pigmentos cerámicos, Faenza editrice ibérica, Castellón, 2001.

[24] K.E. Sickafus, J.M. Wills, Structure of spinel, J. Am. Ceram. Soc. 82(1999) 3279-3292. doi: 10.1111/j.1151-2916.1999.tb02241.x

[25] International Center for Diffraction Data (ICDD) PDF-4+ file, ICDD 04-0060279 
[26] International Center for Diffraction Data (ICDD) PDF-4+ file, ICDD 04-0063593

[27] A. Muan, S. Somiya, Solid state chemistry and its applications, John Wiley, Chichester,1984.

[28] M. Dondi, C. Zanelli, M. Ardit, G. Cruciani, L. Mantovani, M. Tribaudino, G.

B. Andreozzi, Ni-free, black ceramic pigments based on $\mathrm{Co}-\mathrm{Cr}-\mathrm{Fe}-\mathrm{Mn}$ spinels: A reappraisal of crystal structure, colour and technological behavior, Ceram. Int. 39 (2013) 9533-9547. doi: 10.1016/j.ceramint.2013.05.072

[29] J. Gilabert, M.D. Palacios, V. Sanz, S. Mestre, Characteristics reproducibility of $(\mathrm{Fe}, \mathrm{Co})(\mathrm{Cr}, \mathrm{Al})_{2} \mathrm{O}_{4}$ pigments obtained by solution combustion synthesis, Ceram. Int. 42 (2016) 12880-12887. doi:10.1016/j.ceramint.2016.05.054

[30] S. Mestre, M.D. Palacios, P. Agut, Solution combustion synthesis of $(\mathrm{Co}, \mathrm{Fe}) \mathrm{Cr}_{2} \mathrm{O} 4$ pigments, J. Eur. Ceram. Soc. 32 (9) (2012) 1995-1999. doi:10.1016/j.jeurceramsoc.2011.11.044

[31] R. G. Ianos, Temperature and atmosphere influence during combustion synthesis of metal oxide (nano)powders, $\mathrm{PhD}$ thesis, Politehnica University of Timișoara, Faculty of Industrial Chemistry and Environmental Engineering, 2015.

[32] S. Désilets, P. Brousseau, D. Chamberland, S. Singh. H. Feng, R. Turcotte, K. Armstrong, J. Anderson, Analyses of the thermal decomposition of urea nitrate at high temperature, Thermochimica Acta, 521 (2011) 59-65. doi: 10.1016/j.tca.2011.04.004

[33] T. Hatakeyama, L. Zhenhai (eds.) Handbook of thermal analysis. Reimp. Chichester: John Wiley \& sons, 2000. 
[34] A. Escardino, S. Mestre, A. Barba, V. Beltrán, A. Blasco, Synthesis mechanism of an iron-chromium ceramic pigment, J. Am. Ceram. Soc. 83 (1) (2000) 29-32. doi: $10.1111 / \mathrm{j} .1151-2916.2000 . t b 01143 . x$

[35] T. Maiyalagan, K. R. Chemelewski, A. Manthiram, Role of the morphology and surface planes on the catalytic activity of spinel LiMn1.5Ni0.5O4 for oxygen evolution reaction, ACS Catal. 4, (2014) 421-425. doi: 10.1021/cs400981d

[36] S.H. Murdock, R.A. Eppler, Zinc Iron chromite pigments, J. Am. Ceram. Soc. 71 (1988) C212-C214.

[37] R.A. Eppler, Cobalt-free black pigments, Ceram. Bull. 60 (1981) 562-565

[38] S. Mestre, Compuestos del sistema $\mathrm{Fe}_{2} \mathrm{O}_{3}-\mathrm{Cr}_{2} \mathrm{O}_{3}$, estudio cinético y colorimétrico, PhD Thesis, Castellón, Universitat Jaume I, 1997. 


\section{Figure captions}

Figure 1 SCS scheme followed in the lab with subsequent calcination steps

Figure $2 \mathrm{XRD}$ phase identification for all composition range of $\mathrm{Ni}_{1-\Psi} \mathrm{Fe}_{\Psi} \mathrm{Cr}_{2} \mathrm{O}_{4}(0 \leq$ $\Psi \leq 1$ ) of the as-synthesized samples (• spinel, o eskolaite-type phase)

Figure 3 Evolution of the XRD main peak of the crystalline phases identified in the pigments versus $\Psi, \mathrm{T}_{\mathrm{c}}$ and kiln atmosphere

Figure 4 Evolution of phase percentage and crystal size depending on parameter $\Psi$,

$\mathrm{T}_{\mathrm{c}}$ and kiln atmosphere

Figure 5 Comparison of the lattice parameter of spinels with the prediction of

Vegard's law, based on the ICCD data from the $\mathrm{NiCr}_{2} \mathrm{O}_{4}(\Psi=0.0)$ and $\mathrm{FeCr}_{2} \mathrm{O}_{4}(\Psi=$ 1.0)

Figure 6 TGA curves for sample $\Psi=1.0$ at two different atmospheres (Air and $\mathrm{N}_{2}$ )

Figure 7 Micrographies obtained by SEM of synthesized pigments

Figure 8 Example of glazed as-synthesized samples showing saturated colours with no defects on the surface

Figure 9 Reflectance curves of the glazes that contain the synthesized pigments Figure 10 Evolution of chromatic coordinates of glaze versus composition of the incorporated pigment: a) $\mathrm{L}^{*}$ and $\mathrm{b}^{*}$ coordinates and b) $\mathrm{a}^{*}$ coordinate 


\section{Tables and table captions}

Table 1 Initial solution composition for each synthesized spinel

\begin{tabular}{|c|c|c|c|c|}
\hline \multirow{3}{*}{ Ref. } & \multirow{3}{*}{$\Psi$} & $\mathrm{Ni}\left(\mathrm{NO}_{3}\right)_{2}$ & $\mathrm{Fe}\left(\mathrm{NO}_{3}\right)_{3}$ & $\mathrm{Cr}\left(\mathrm{NO}_{3}\right)_{3}$ \\
\hline & & $\cdot 6 \mathrm{H}_{2} \mathrm{O}$ & $\cdot 9 \mathrm{H}_{2} \mathrm{O}$ & $\cdot 9 \mathrm{H}_{2} \mathrm{O}$ \\
\hline & & (g) & (g) & (g) \\
\hline S1 & 0.0 & 17.4 & 0.0 & 48.0 \\
\hline S2 & 0.2 & 13.6 & 4.7 & 46.8 \\
\hline S3 & 0.4 & 10.0 & 9.2 & 45.7 \\
\hline S4 & 0.6 & 6.5 & 13.5 & 44.6 \\
\hline S5 & 0.8 & 3.2 & 17.6 & 43.6 \\
\hline S6 & 1.0 & 0.0 & 21.5 & 42.6 \\
\hline
\end{tabular}

Table 2 Crystal structural data of as-synthesized and calcined pigments: unit cell parameters and estimated crystal chemistry

\begin{tabular}{|c|c|c|c|c|c|c|c|c|}
\hline \multirow[b]{2}{*}{ Ref } & \multirow[b]{2}{*}{$\Psi$} & \multirow[b]{2}{*}{$\begin{array}{l}\text { Post- } \\
\text { synthesis } \\
\text { conditions }\end{array}$} & \multicolumn{4}{|c|}{ Cell parameters } & \multicolumn{2}{|c|}{ Crystal chemistry } \\
\hline & & & $\begin{array}{l}\text { Spinel } \\
\text { a }(\AA)\end{array}$ & a $(\AA)$ & c $(\AA)$ & $\begin{array}{l}\text { Spinel } \\
\text { oxygen } \\
\text { parameter } \\
\text { (adim.) }\end{array}$ & $\begin{array}{c}\mathrm{Ni}_{1-\mathrm{x}} \mathrm{Fe}_{\mathrm{x}} \mathrm{Cr}_{2^{-}} \\
{ }_{\mathrm{y}} \mathrm{Fe}_{\mathrm{y}} \mathrm{O}_{4}\end{array}$ & $\underset{{ }_{\mathrm{z}}}{\left(\mathrm{Fe}_{\mathrm{z}}\right) \mathrm{O}_{3}}$ \\
\hline 1 & 0.0 & & 8.315 & 4.992 & 13.518 & 0.2290 & $\mathrm{NiCr}_{2} \mathrm{O}_{4}$ & $\mathrm{Cr}_{2} \mathrm{O}_{3}$ \\
\hline 2 & 0.2 & & 8.312 & 4.958 & 13.591 & 0.2494 & $\mathrm{Ni}_{0.84} \mathrm{Fe}_{0.16} \mathrm{Cr}_{2} \mathrm{O}_{4}$ & $\mathrm{Cr}_{1.40} \mathrm{Fe}_{0.60} \mathrm{O}_{3}$ \\
\hline 3 & 0.4 & As- & 8.304 & 4.956 & 13.584 & 0.2559 & $\mathrm{Ni}_{0.63} \mathrm{Fe}_{0.37} \mathrm{Cr}_{2} \mathrm{O}_{4}$ & $\mathrm{Cr}_{1.39} \mathrm{Fe}_{0.61} \mathrm{O}_{3}$ \\
\hline 4 & 0.6 & synthesized & 8.305 & 4.950 & 13.578 & 0.2564 & $\mathrm{Ni}_{0.43} \mathrm{Fe}_{0.57} \mathrm{Cr}_{2} \mathrm{O}_{4}$ & $\mathrm{Cr}_{1.38} \mathrm{Fe}_{0.62} \mathrm{O}_{3}$ \\
\hline 5 & 0.8 & & 8.305 & 4.999 & 13.479 & 0.2607 & $\mathrm{Ni}_{0.21} \mathrm{Fe}_{0.79} \mathrm{Cr}_{2} \mathrm{O}_{4}$ & $\mathrm{Cr}_{1.38} \mathrm{Fe}_{0.62} \mathrm{O}_{3}$ \\
\hline 6 & 1.0 & & 8.305 & 4.966 & 13.589 & 0.2610 & $\mathrm{FeCr}_{2} \mathrm{O}_{4}$ & $\mathrm{Cr}_{1.39} \mathrm{Fe}_{0.61} \mathrm{O}_{3}$ \\
\hline
\end{tabular}




\begin{tabular}{|c|c|c|c|c|c|c|c|c|}
\hline 7 & 0.0 & & 8.316 & 4.999 & 13.509 & 0.2275 & $\mathrm{NiCr}_{2} \mathrm{O}_{4}$ & $\mathrm{Cr}_{2} \mathrm{O}_{3}$ \\
\hline 8 & 0.2 & & 8.315 & 4.964 & 13.592 & 0.2568 & $\mathrm{NiCr}_{2} \mathrm{O}_{4}$ & $\mathrm{Cr}_{1.38} \mathrm{Fe}_{0.62} \mathrm{O}_{3}$ \\
\hline 9 & 0.4 & & 8.311 & 4.971 & 13.593 & 0.2591 & $\mathrm{NiCr}_{2} \mathrm{O}_{4}$ & $\mathrm{Cr}_{1.37} \mathrm{Fe}_{0.63} \mathrm{O}_{3}$ \\
\hline 10 & 0.6 & & 8.306 & 4.978 & 13.594 & 0.2602 & $\mathrm{NiCr}_{2} \mathrm{O}_{4}$ & $\mathrm{Cr}_{1.36} \mathrm{Fe}_{0.64} \mathrm{O}_{3}$ \\
\hline 11 & 0.8 & & 8.302 & 4.986 & 13.600 & 0.2606 & $\mathrm{NiCr}_{2} \mathrm{O}_{4}$ & $\mathrm{Cr}_{1.35} \mathrm{Fe}_{0.65} \mathrm{O}_{3}$ \\
\hline 12 & 1.0 & & 8.302 & 4.990 & 13.604 & 0.2611 & $\mathrm{FeCr}_{2} \mathrm{O}_{4}$ & $\mathrm{Cr}_{1.34} \mathrm{Fe}_{0.66} \mathrm{O}_{3}$ \\
\hline 13 & 0.0 & & 8.313 & 4.990 & 13.495 & 0.2162 & $\mathrm{NiCr}_{2} \mathrm{O}_{4}$ & $\mathrm{Cr}_{2} \mathrm{O}_{3}$ \\
\hline 14 & 0.2 & & 8.316 & 4.963 & 13.590 & 0.2540 & $\mathrm{NiCr}_{2} \mathrm{O}_{4}$ & $\mathrm{Cr}_{1.38} \mathrm{Fe}_{0.62} \mathrm{O}_{3}$ \\
\hline 15 & 0.4 & & 8.312 & 4.969 & 13.594 & 0.2557 & $\mathrm{NiCr}_{2} \mathrm{O}_{4}$ & $\mathrm{Cr}_{1.38} \mathrm{Fe}_{0.62} \mathrm{O}_{3}$ \\
\hline 16 & 0.6 & & 8.301 & 4.974 & 13.592 & 0.2539 & $\mathrm{NiCr}_{2} \mathrm{O}_{4}$ & $\mathrm{Cr}_{1.36} \mathrm{Fe}_{0.64} \mathrm{O}_{3}$ \\
\hline 17 & 0.8 & & 8.299 & 4.985 & 13.604 & 0.2562 & $\mathrm{NiCr}_{2} \mathrm{O}_{4}$ & $\mathrm{Cr}_{1.35} \mathrm{Fe}_{0.65} \mathrm{O}_{3}$ \\
\hline 18 & 1.0 & & 8.299 & 4.993 & 13.611 & 0.2611 & $\mathrm{FeCr}_{2} \mathrm{O}_{4}$ & $\mathrm{Cr}_{1.34} \mathrm{Fe}_{0.66} \mathrm{O}_{3}$ \\
\hline 19 & 0.0 & & 8.318 & 4.997 & 13.606 & 0.2376 & $\mathrm{NiCr}_{2} \mathrm{O}_{4}$ & $\mathrm{Cr}_{2} \mathrm{O}_{3}$ \\
\hline 20 & 0.2 & & 8.316 & 4.965 & 13.594 & 0.2558 & $\mathrm{NiCr}_{2} \mathrm{O}_{4}$ & $\mathrm{Cr}_{1.38} \mathrm{Fe}_{0.62} \mathrm{O}_{3}$ \\
\hline 21 & 0.4 & $1000^{\circ} \mathrm{C}$ & 8.312 & 4.971 & 13.595 & 0.2567 & $\mathrm{NiCr}_{2} \mathrm{O}_{4}$ & $\mathrm{Cr}_{1.37} \mathrm{Fe}_{0.63} \mathrm{O}_{3}$ \\
\hline 22 & 0.6 & $\left(\mathrm{~N}_{2}\right)$ & 8.297 & 4.973 & 13.593 & 0.2610 & $\mathrm{Ni}_{0.93} \mathrm{Fe}_{0.07} \mathrm{Cr}_{2} \mathrm{O}_{4}$ & $\mathrm{Cr}_{1.35} \mathrm{Fe}_{0.65} \mathrm{O}_{3}$ \\
\hline 23 & 0.8 & & 8.280 & 4.979 & 13.601 & 0.2610 & $\mathrm{Ni}_{0.56} \mathrm{Fe}_{0.44} \mathrm{Cr}_{2} \mathrm{O}_{4}$ & $\mathrm{Cr}_{1.35} \mathrm{Fe}_{0.65} \mathrm{O}_{3}$ \\
\hline 24 & 1.0 & & 8.262 & 4.989 & 13.612 & 0.2612 & $\mathrm{FeCr}_{2} \mathrm{O}_{4}$ & $\mathrm{Cr}_{1.34} \mathrm{Fe}_{0.66} \mathrm{O}_{3}$ \\
\hline
\end{tabular}

Table 3 Specific surface area values $\left(\mathrm{m}^{2} / \mathrm{g}\right)$ for selected samples

\begin{tabular}{llll}
\hline Temperature $\left({ }^{\circ} \mathrm{C}\right)$ & Kiln atmosphere & Composition & \\
& & $\Psi=0.0$ & $\Psi=1.0$ \\
\hline 500 & Air & 11.7 & 7.7 \\
1000 & Air & 18.8 & 3.3 \\
1000 & $\mathrm{~N}_{2}$ & 7.0 & 3.9 \\
\hline
\end{tabular}




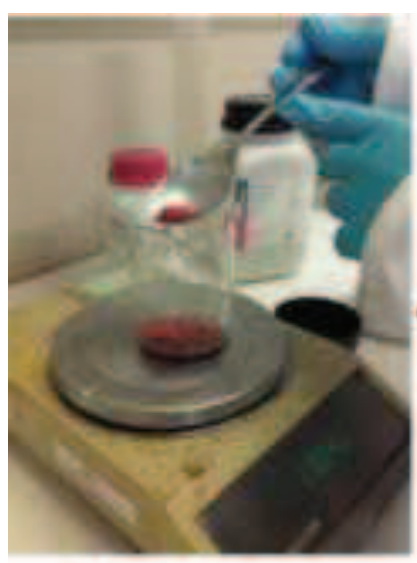

Dosage

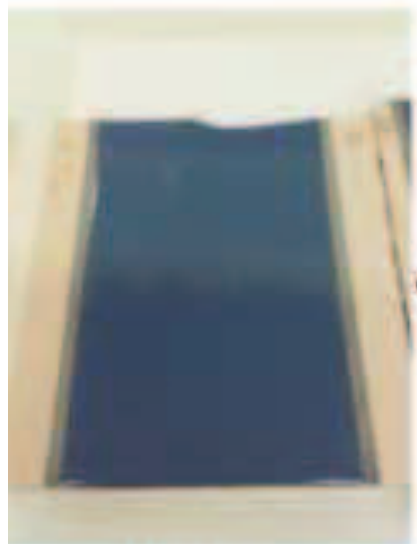

Firing

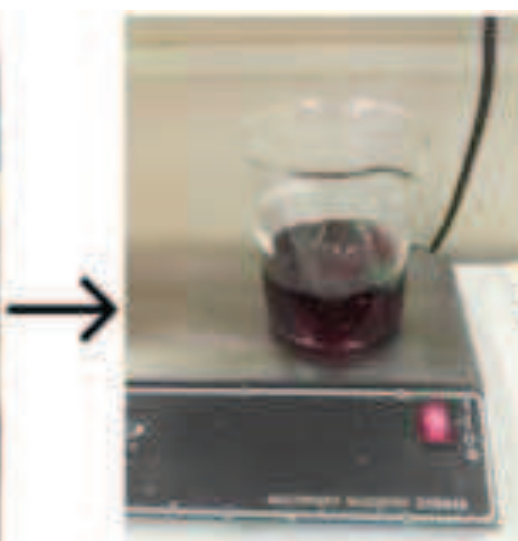

Mixing

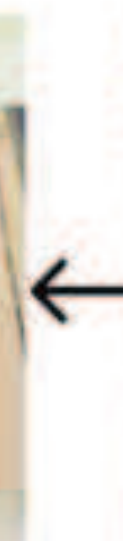

8

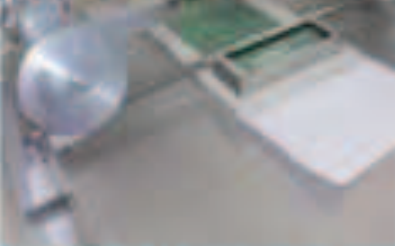

Glazing

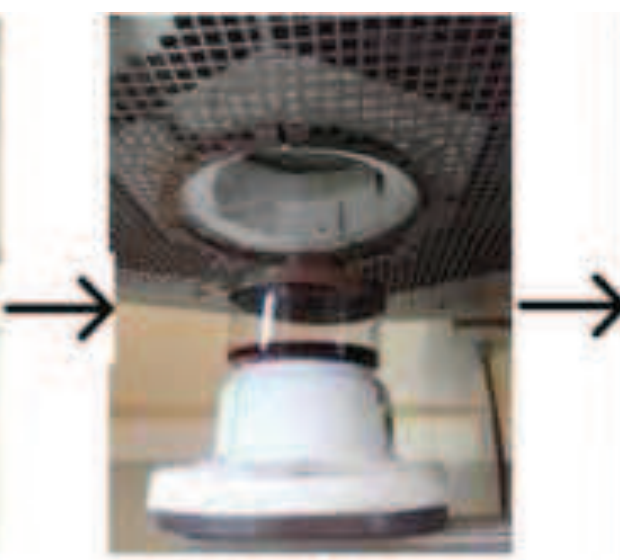

Synthesis

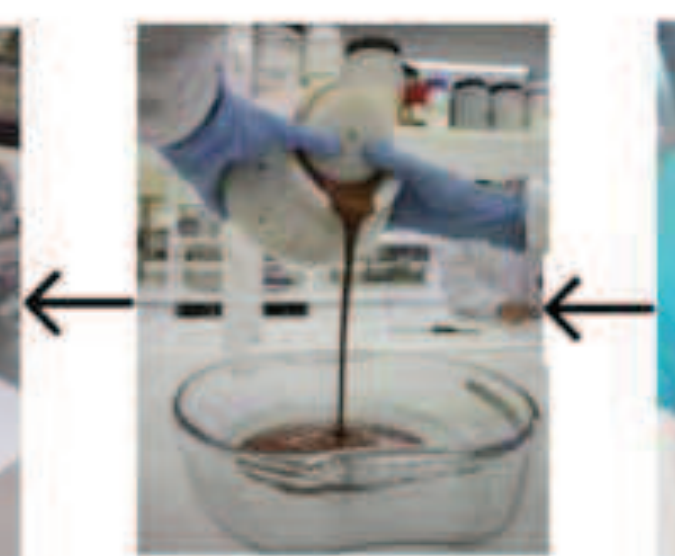

Addition to glaze

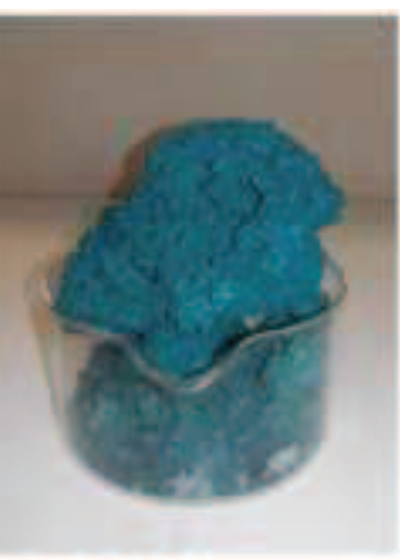

SCS Pigment

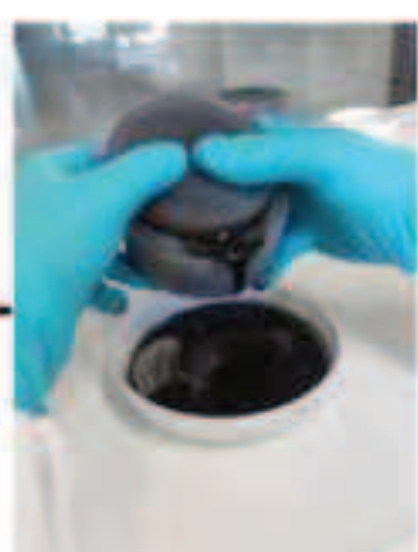

Wet milling

\section{$\searrow$}

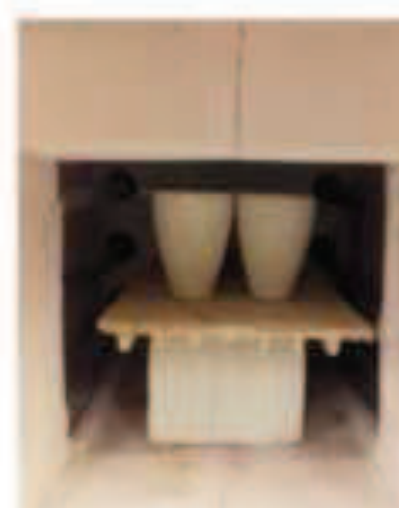

Calcination

L 


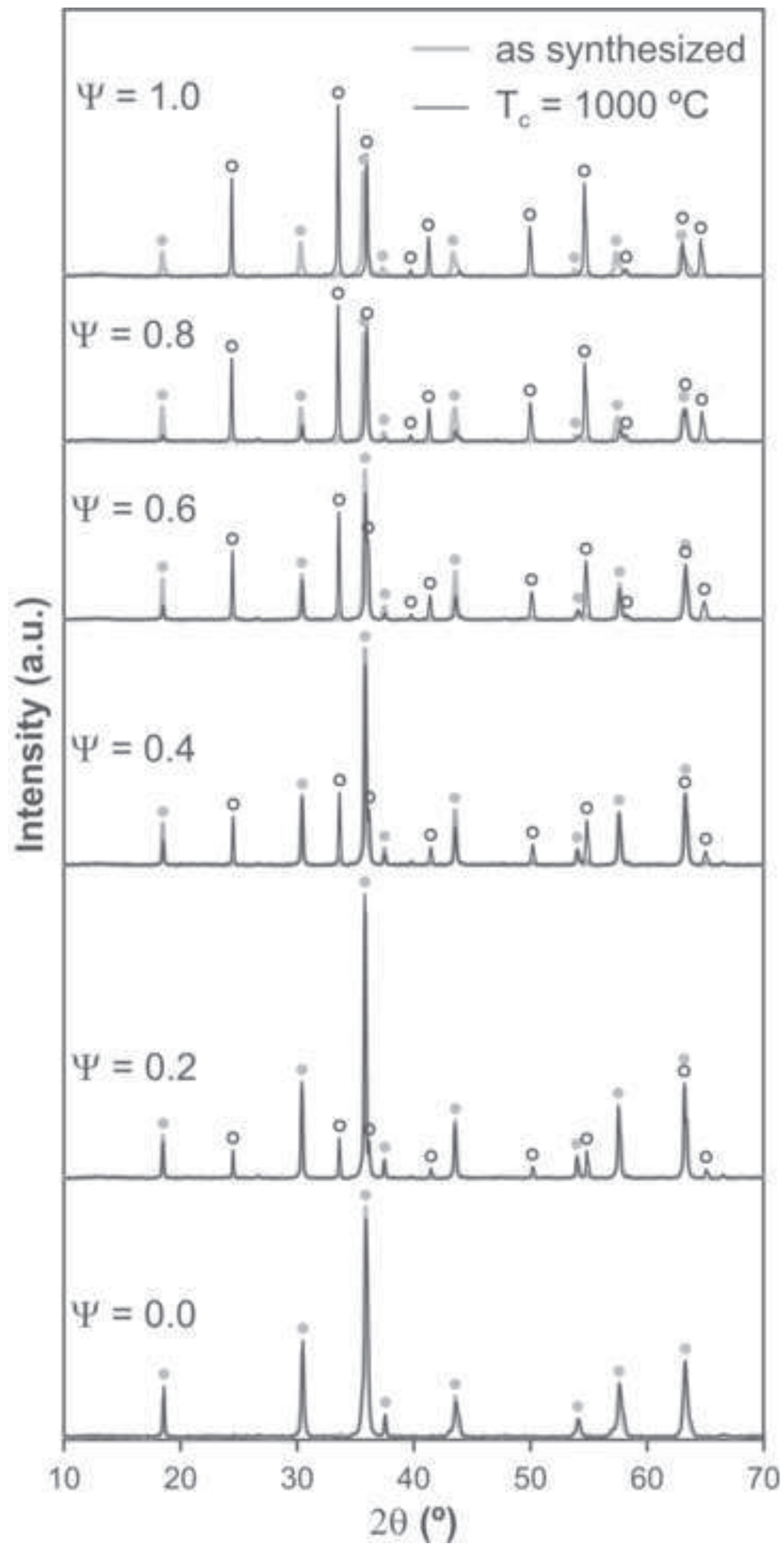



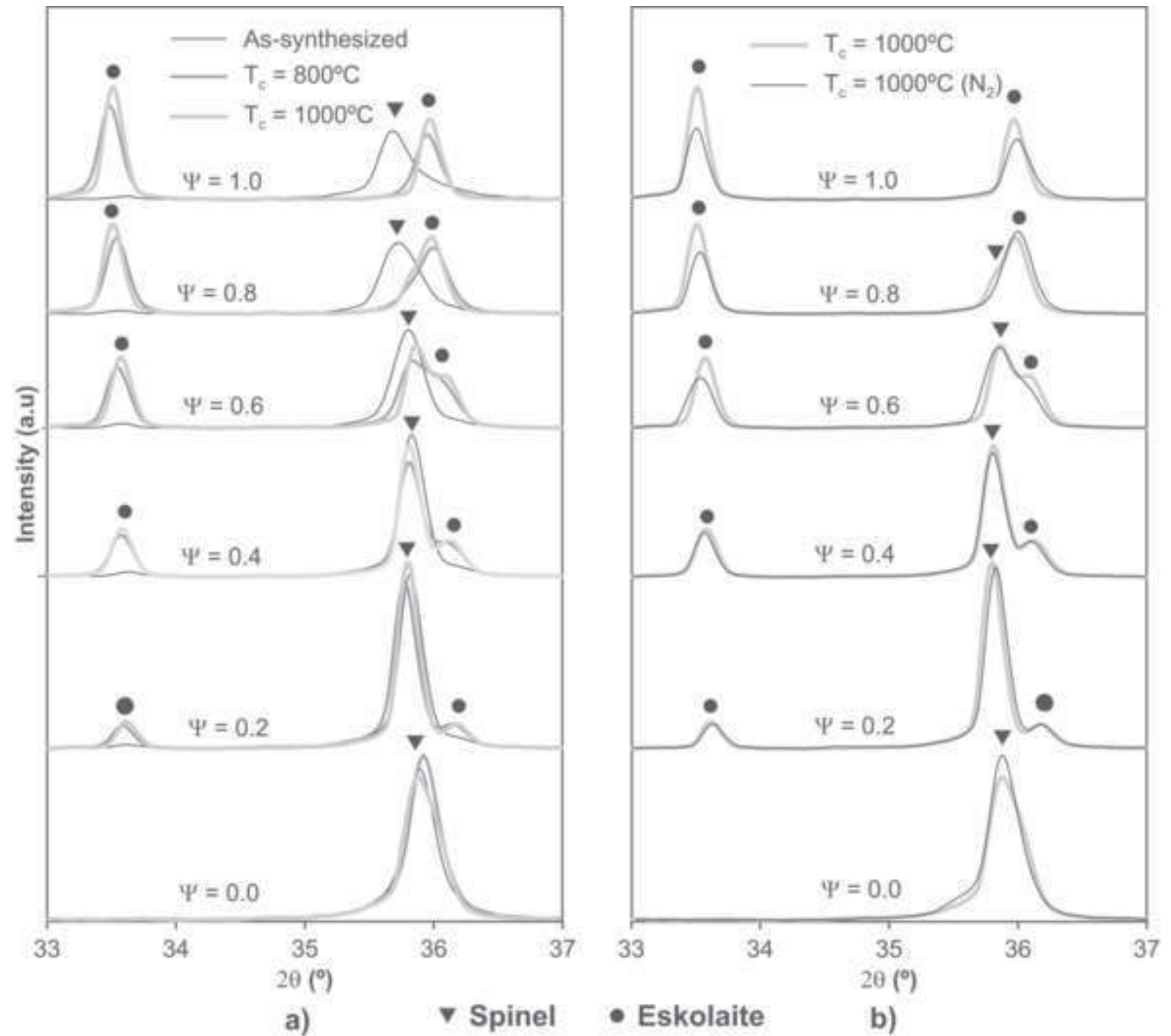
Click here to download high resolution image
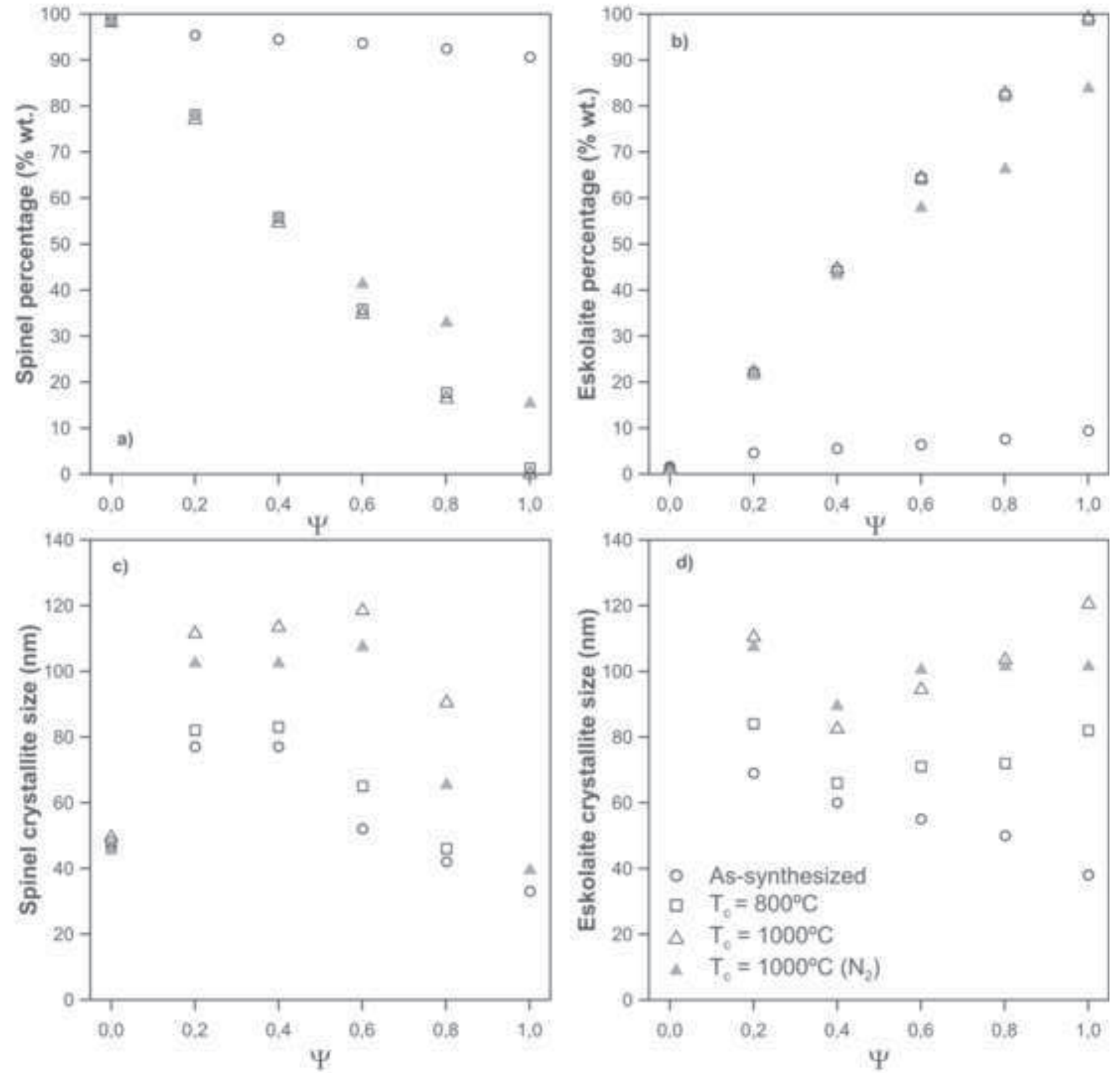


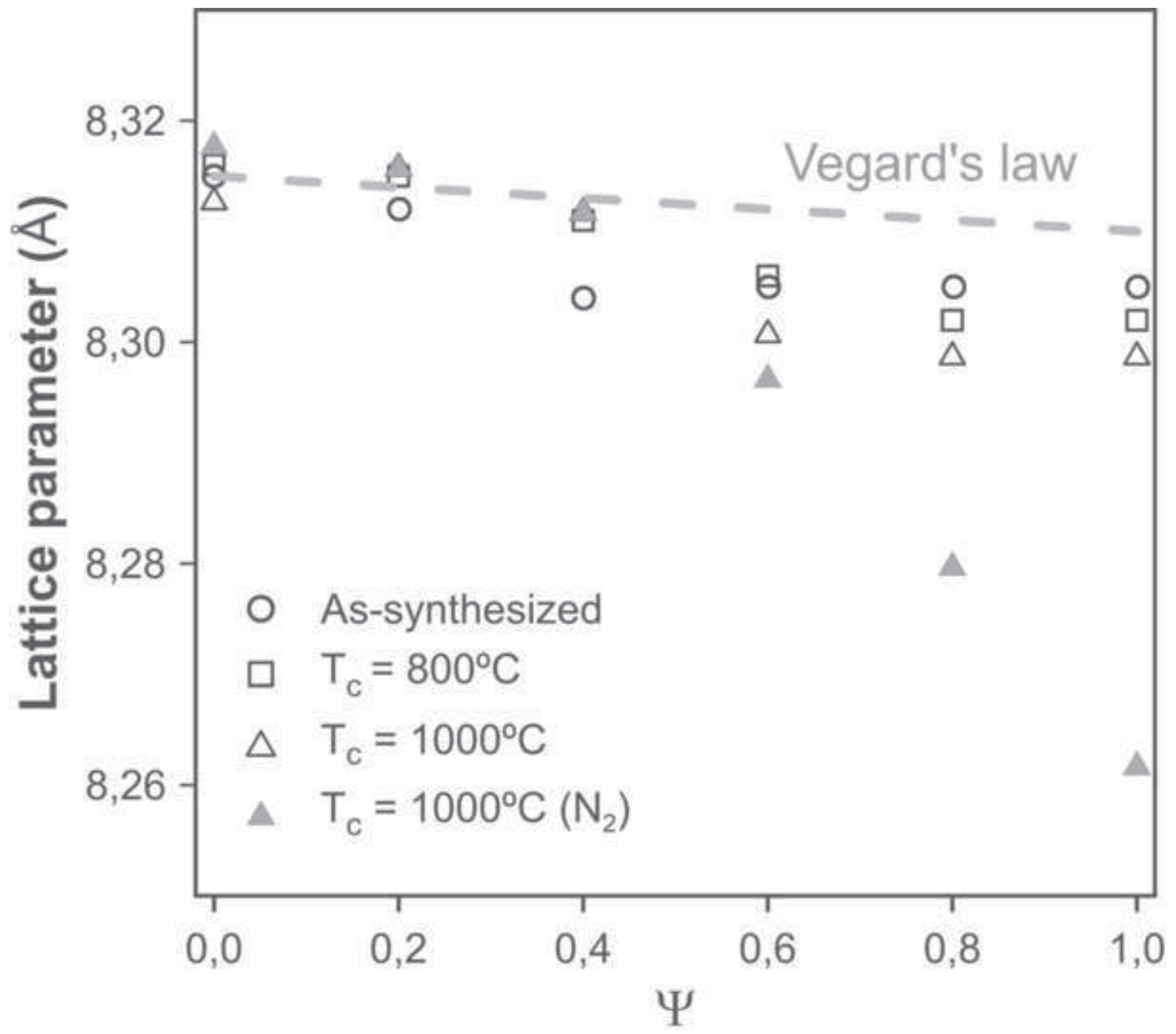




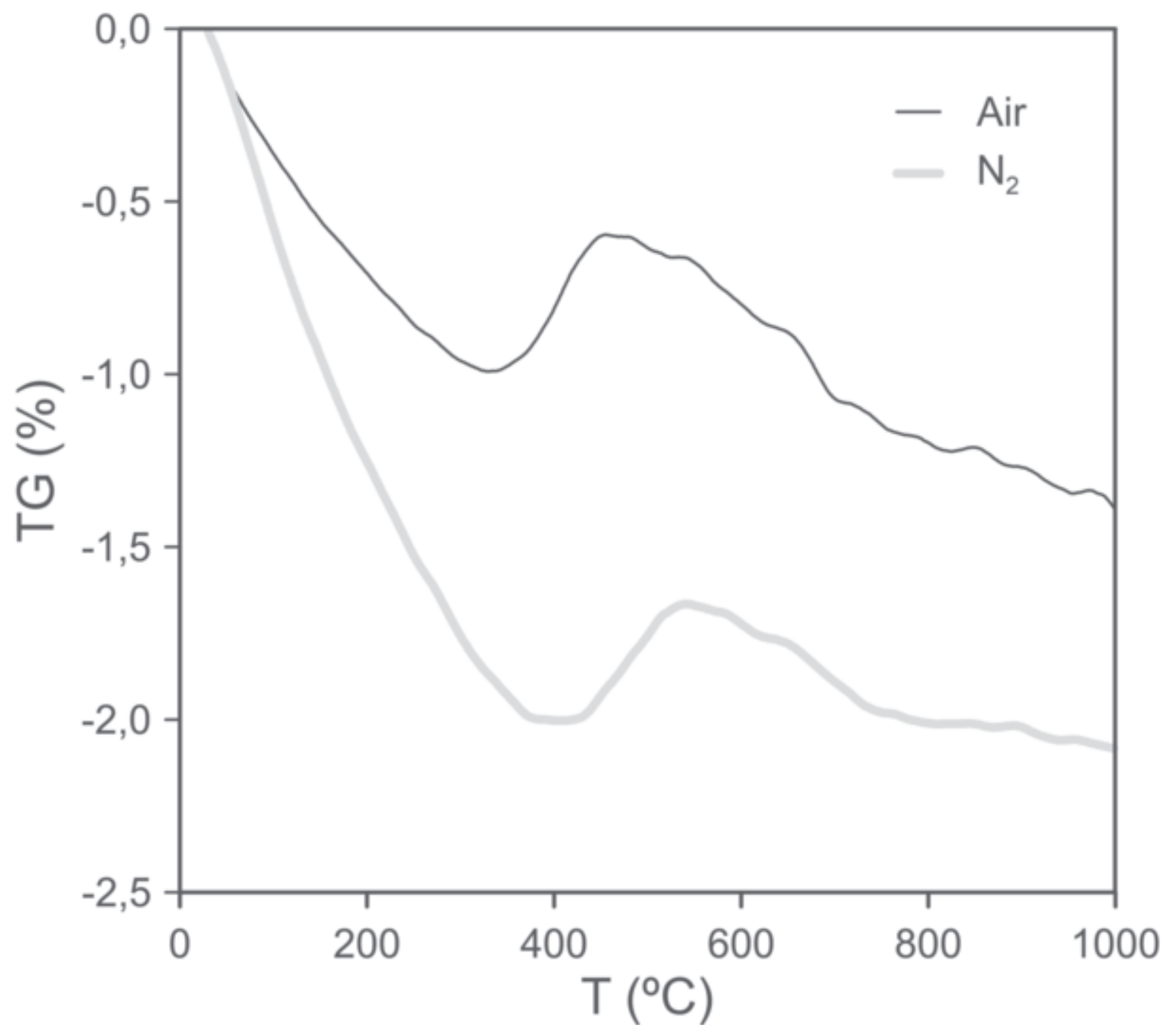



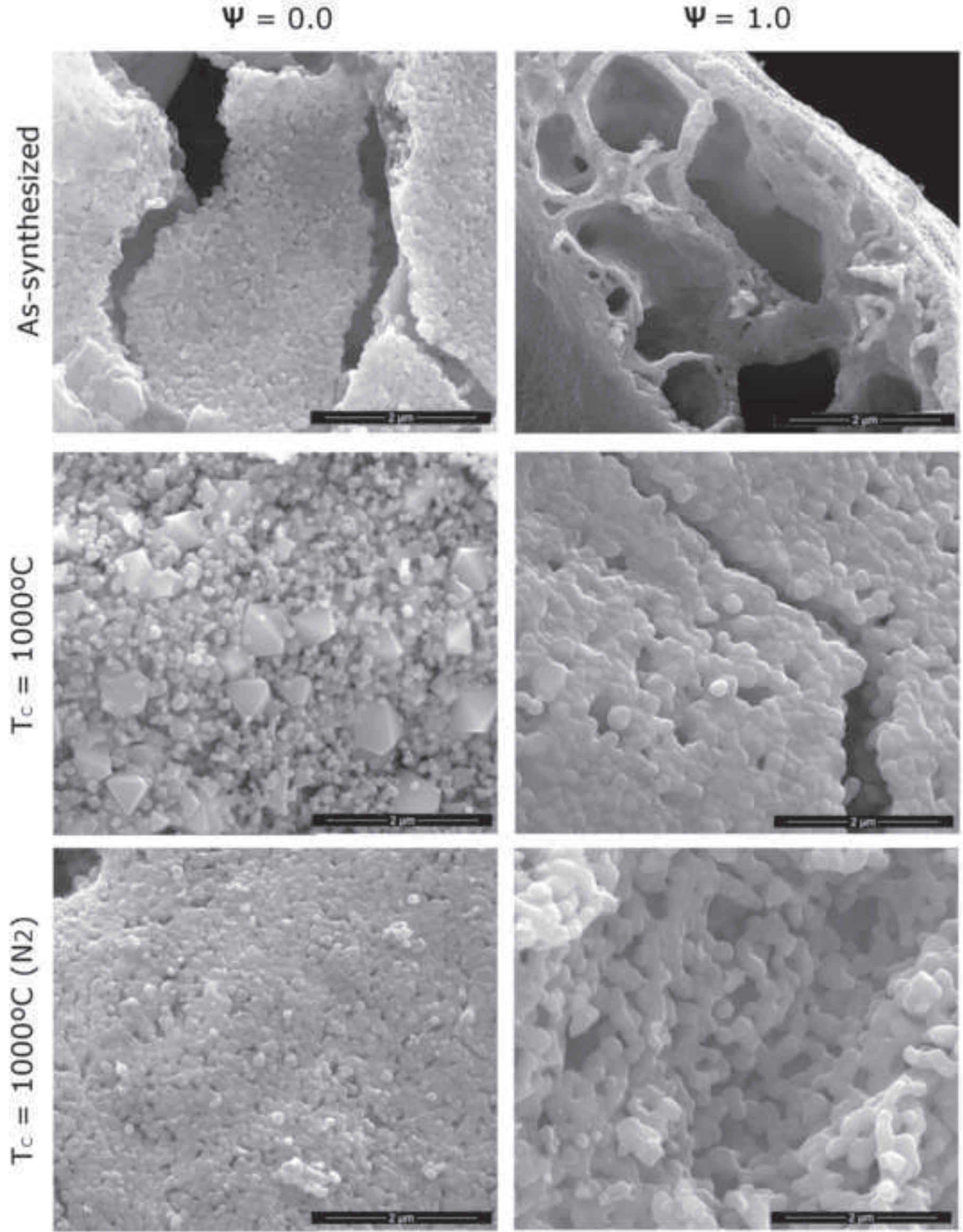


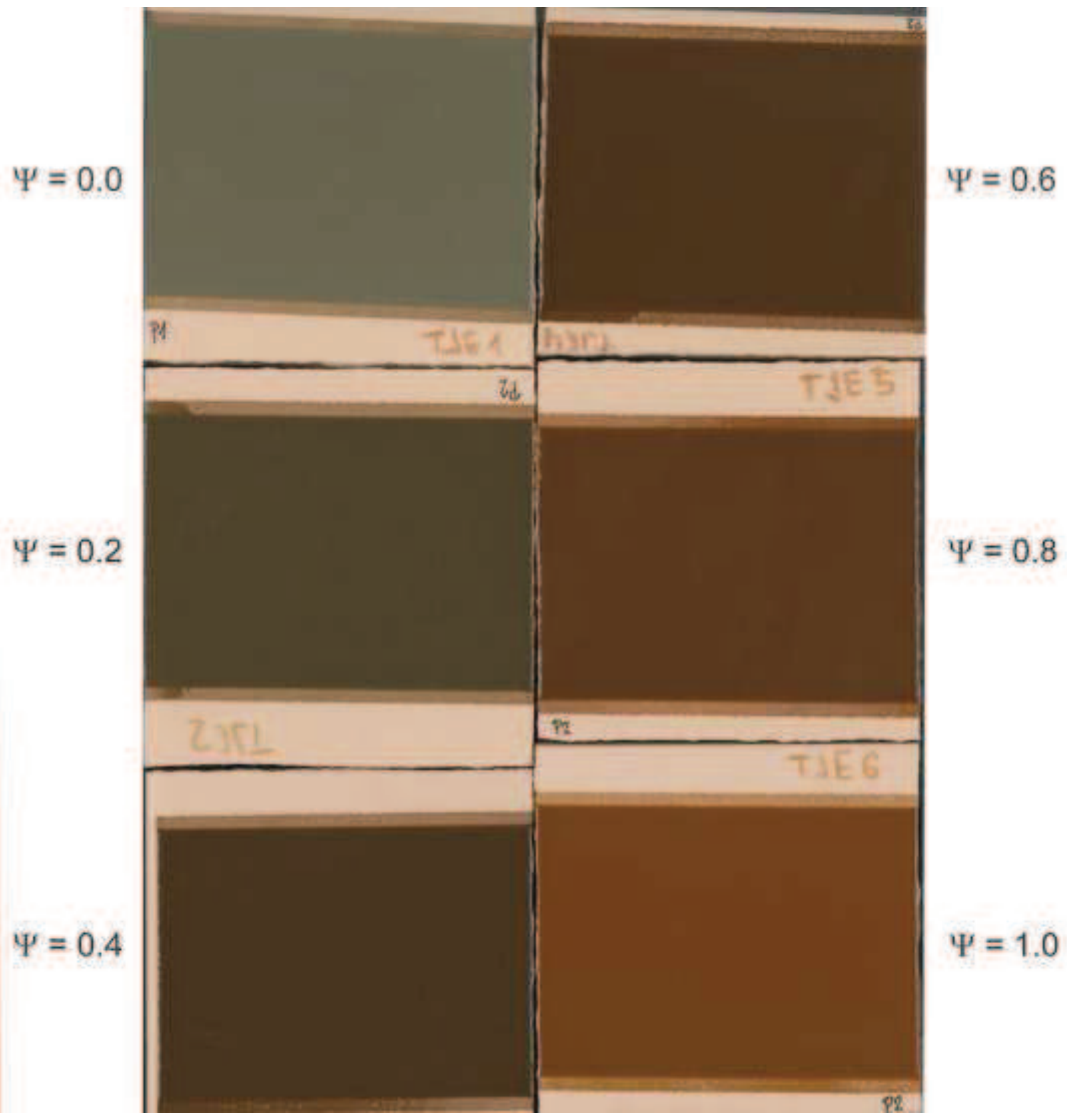




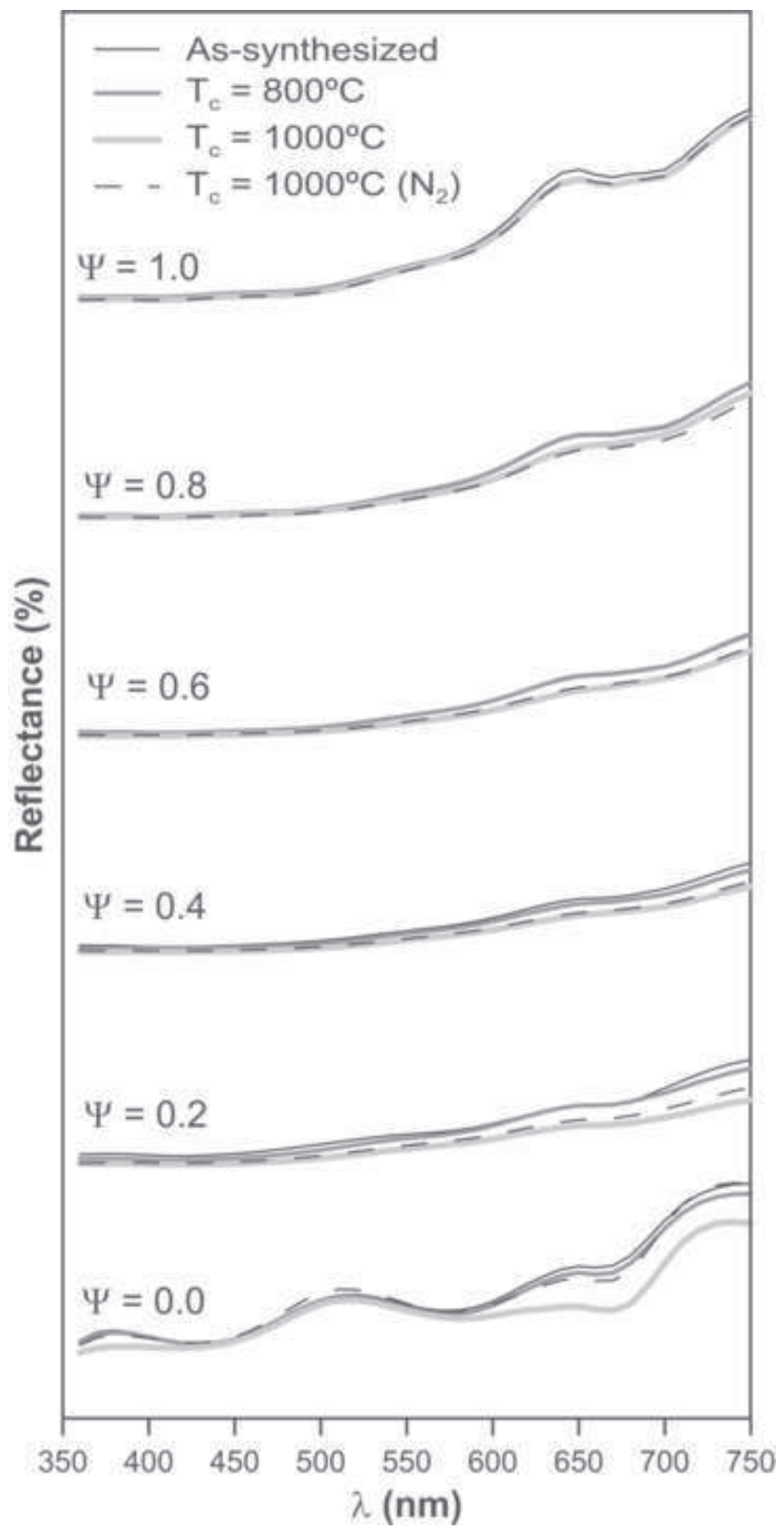




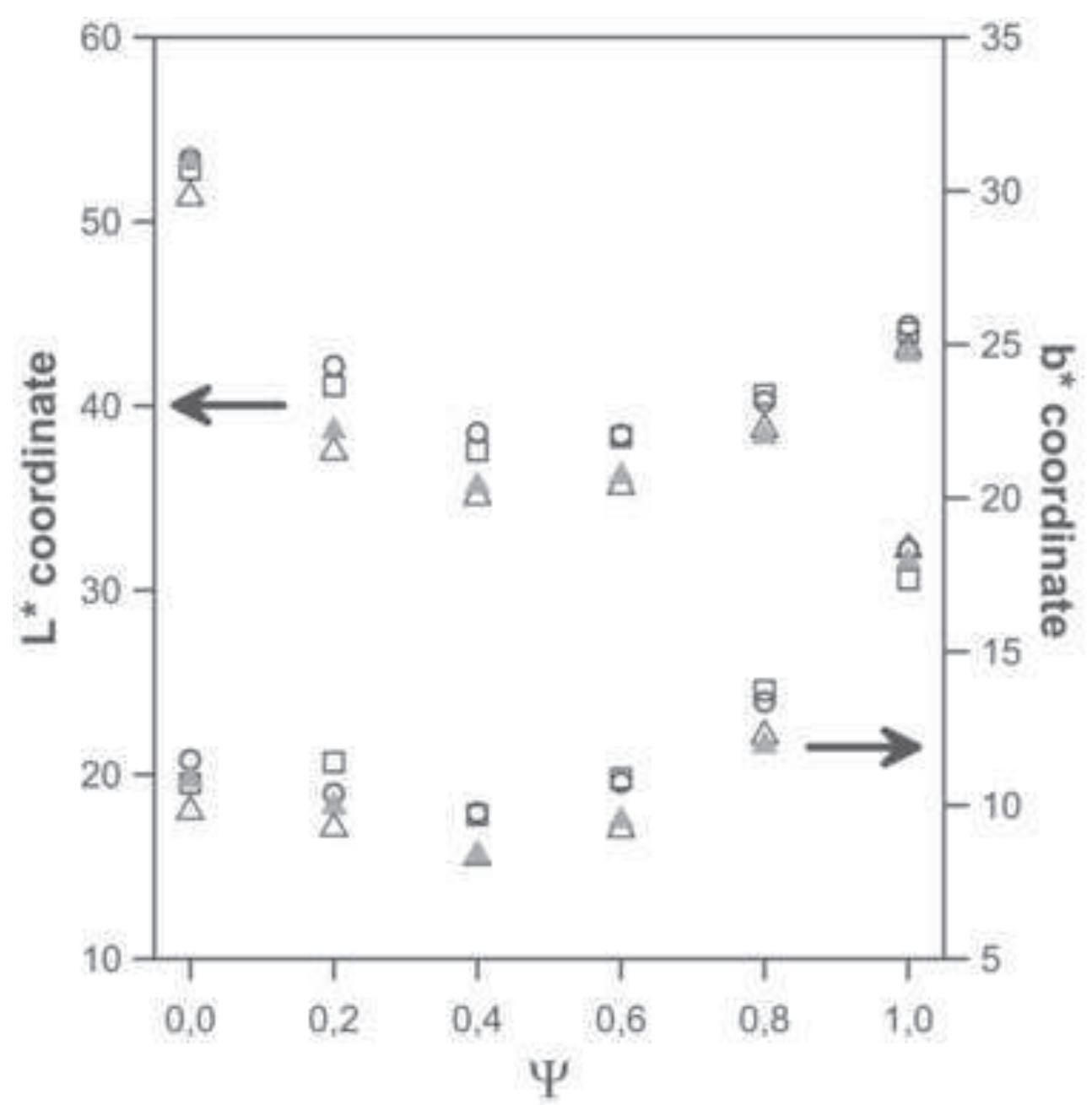

a)

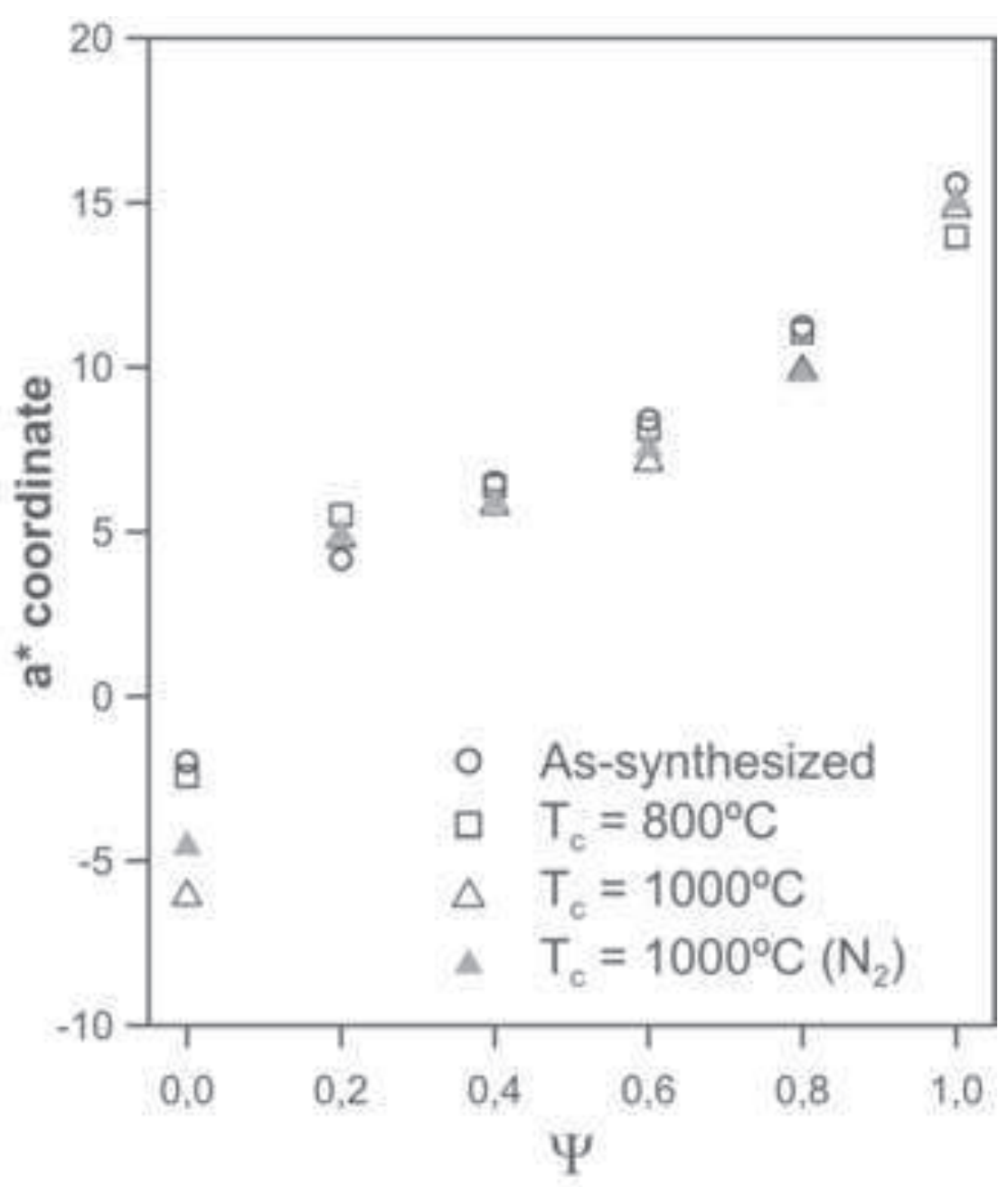

b) 